FATiH SULTAN MEHMET
FSM ilmî Araştırmalar Insan ve Toplum Bilimleri Dergisi FSM Scholarly Studies Journal of Humanities and Social Sciences Sayı/Number 8 Yıl/Year 2016 Güz/Autumn

(c) 2016 Fatih Sultan Mehmet Vakıf Üniversitesi

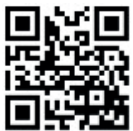

http://dergipark.gov.tr/fsmia - http://dergi.fsm.edu.tr

Araştırma Makalesi / Research Article - Geliş Tarihi / Received: 13.04.2016 Kabul Tarihi / Accepted: 29.05.2016 - FSMIAD, 2016; (8): 181-202

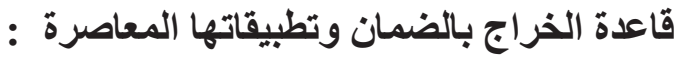 المرابحة للآمر بالثر اء في البنك الإسلامي الأردني (Suhel Ahmad Fadel Hawamdeh)* سعيل احمد فضل حو امده \\ الملخص
}

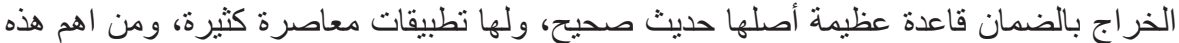

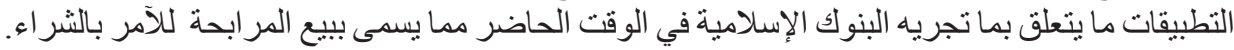

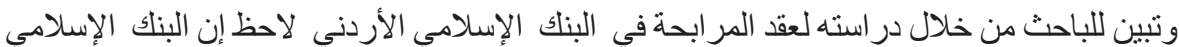

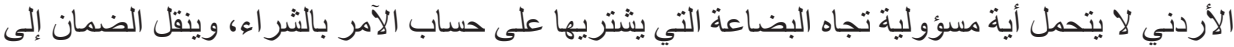

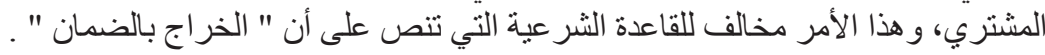
الكلمات الافتتاحية: الخر اج بالضمان، بنوك اسلامية، المر ابحة .

$$
\text { * ... جامعة اسطنبول صباح الدين الزعيم كلية العلوم الإسلامية ,اسطنبول / التركية }
$$

Yrd. Doç. Dr., İstanbul Sabahattin Zaim Üniversitesi İslami İlimler Fakültesi, İstanbul/Türkiye, arzaqtube2016@gmail.com 


\section{“Nimet Külfet Karşıı̆̆ıdır" Kaidesi ve Çağdaş Uygulamaları: Ürdün İslam Bankasında Satın Alma Talimatı Veren Adına Murabaha İşlemleri}

\section{$\ddot{O} \mathbf{z}$}

"Nimet külfet karşılığıdır” kaidesi büyük bir kaide olup, sahih bir hadise dayanmaktadır. Bu kaidenin günümüzde pek çok uygulaması vardır. Bunların en önemlilerinden biri de, günümüzde İslam bankalarının uyguladığ 1 ve "satın alma talimatı veren adına murabaha satışı" adı verilen işlemdir.

Araştırmacı Ürdün İslam Bankasında yaptığı araştırmalarının neticesinde açıkça şunu görmüştür: Ürdün İslam Bankası satın alma talimatı veren kimsenin adına almış olduğu mal dolayısıyla herhangi bir sorumluluk yüklenmemekte, tazminat külfetini müşteriye aktarmaktadır. Bu durum ise nimetin külfet karşılı̆̆ olduğunu açıkça ifade eden Şer'î kaideye aykırıdır.

Anahtar Kelimeler: Nimet külfet dengesi, İslamî bankalar, Murabaha.

\section{The Rule Kharaj for Guarantee and Contemporary Applications : the Murabaha in the Jordan Islamic Bank}

\section{Abstract}

The kharaj for guarantee a great rule origin hadith, and have many contemporary applications, these applications are the most important terms of what Islamic banks conducted at the present time to sell the so-called Murabaha to buy something. The researcher found, through the study of the Murabaha contract in the Jordan Islamic Bank noted that Jordan Islamic Bank does not assume any responsibility for the goods purchased by the commanding buying account, and transferred security to the buyer, and this is contrary to the legitimate rule, which states that "the abscess security".

Keywords: The kharaj for guarantee, Islamic banks, Murabaha. 


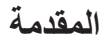

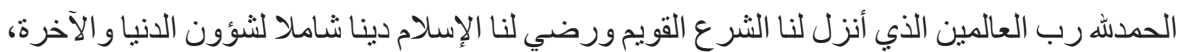

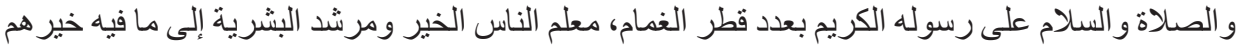

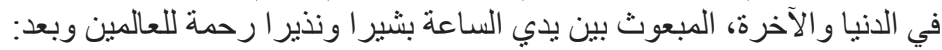

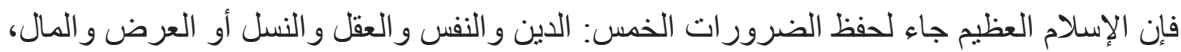

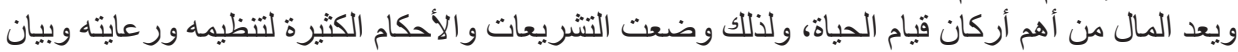

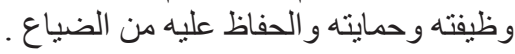

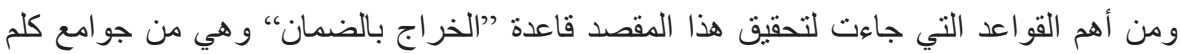

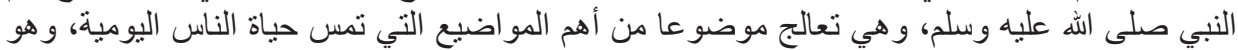

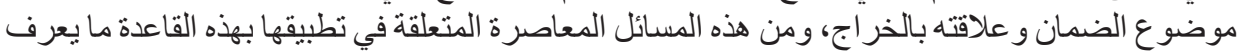

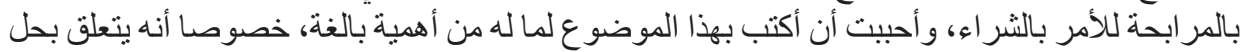

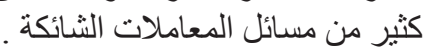

\section{المبحث الأول: شرح قاعدة الخراج بالضمان: المطلب الأول: معنى الخراج بالضمان:}

إن قاعدة الخراج بالضمان من القو اعد المهمة في الفقه الإسلامي، إذ أنها تتعلق بكثير من أبواب الفياب

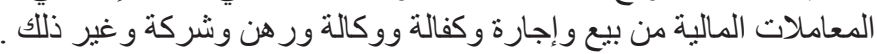

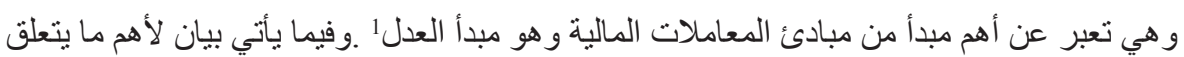

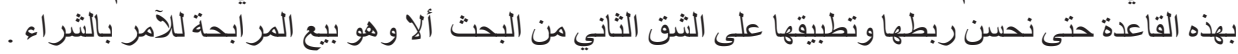

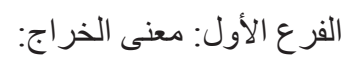

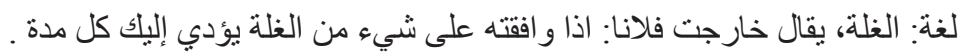

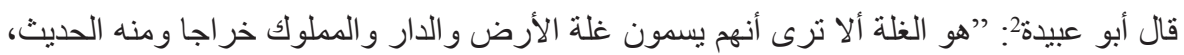

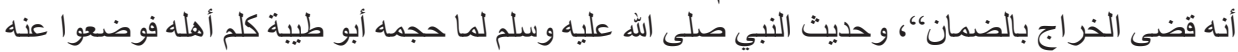

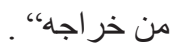
و عرف الخراج: اسم لما يخرج من الفرائض في الأمو ال ويقع على القربة، ويقع على الفيء و على

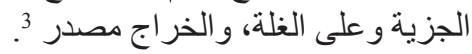
وفي المعجم الوسيط: الخر اج ما يخرج من غلة الأرض، وضن ويقال هذه التفاحة طيب ريحها طيب خر اجها

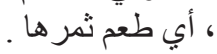

و البلاد الخر اجية: ما فتحت صلحا ووظف من صولح عليها من أهلها على أر اضيهه .

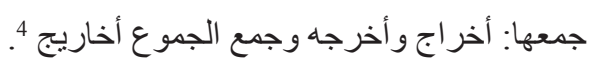

اصطلاحا: ما حصل من غلة العين المبيعة كائنا ما كانت وذلت ألك أن بشتري شيئا ويستغله مدة 5.

1

2 2 2

3 4

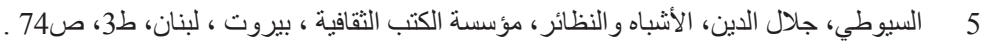


و عرفوه أيضا: هو الغلة الحاصلة من المبيع كأجرة الدابة وكل ما خرج من شيء فهو خر اجه، فخراج

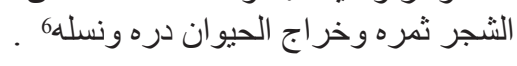

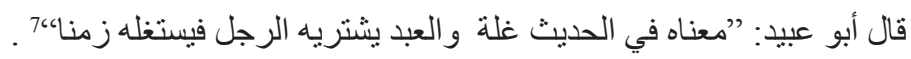
و هناك تعريف للخر اج: هو الذي يخرج من ملك الإنسان، أي ما ينتج منه من النتاج، وما يغل منه من إنس غلات، كغلال الأرض، وبدل إجارة العقار 8. ويمكن أن نعرفه أيضا: هو الناتج المادي المتوقع من نماء ر أس المال الحاصل من توظيفه. الفرع الثاني: معنى الضمان: لغة يطلق على عدة معاني:

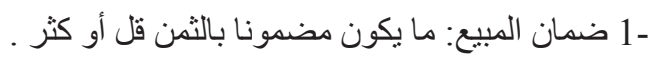
-2 الكفالة: ضمنه الثيء ضمانا، فهو ضامن وضمين إذا كفله . -3 التغريم: نقول ضمنته الثيء تضمينا إذا غرمته فألزمته .

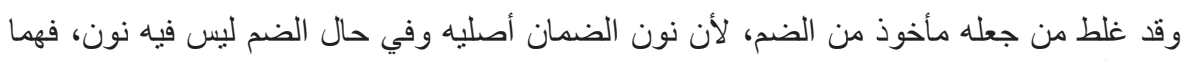
مادتان مختلفتان 9 و أقرب المعاني إلى المعنى الاصطلاحي هو الأول، لأنه متعلق بموضوع القاعدة. اصطلاحا: بطلق بعض الفقهاء الضمان ، ويريدون به ضم ذمة إلى ذمة فيكون هو و الكفالة بمعنى الاونى لإنه واحد.

و البعض الآخر يفرق بين الكفالة والضمان: بأن الكفالة تكون للأبدان و الضمان يكون للأموال، ويطلق

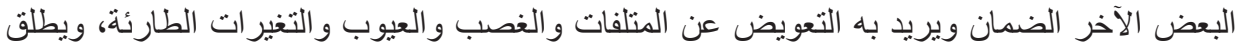
على ضمان المال و التز امه بعقد أو بغير عقد، ويطلق على وضع الئ اليد على العموم بحق أو بغير حق 10 . و هنالك تعريفات أخرى للعلماء منها:

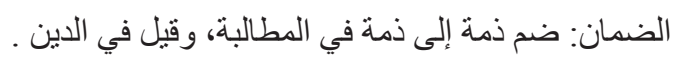

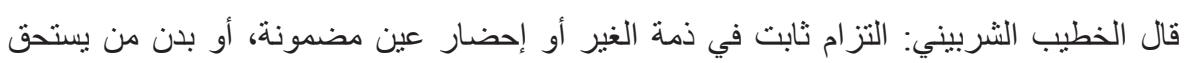
حضوره قال الماوردي: أن العرف جار لاستعمال الضمان في الأمو ال و الكفالة في النفوس 12. و عرف الضمان عبارة عن رد مثل الهالك إن كان مثليا، أو قيمته إن كان قيميا، وقال الضمان الضمان أعم من فن

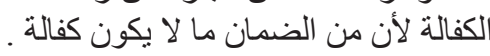

6

7

8 8 المؤلفون- بيت التمويل الكويتي، دليل المصطلحات الفقهية الاقتصادية، ط1 الإ، 1992، ص122 ـ

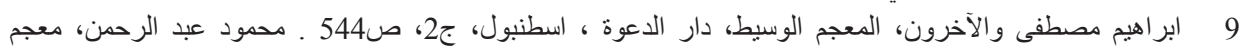

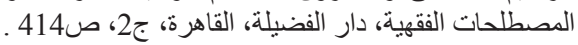
10

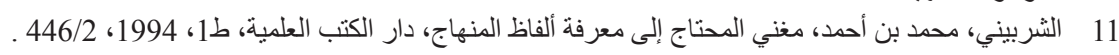

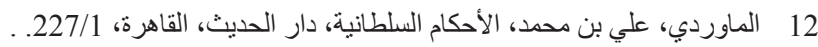


كما يطلق الضمان على غر امة المتلفات و الغصوب و التعييبات و التغيير ات الطارئة 13. كما يطلق على ضمان المال و التز امه بعقد أو بغير عقد . وبالجملة تدور تعريفات الفقهاء للضمان حول المعاني التالية:

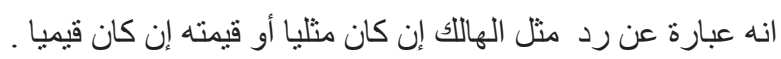

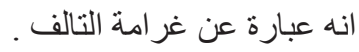
وبالمعنى الذي يشمل الكفالة كما يقول القليوبي: انه التزام دين أو إحضار عين أو بدن أنساف

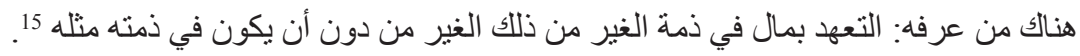

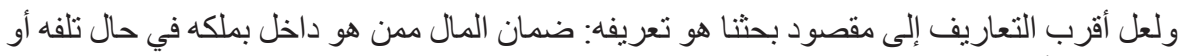

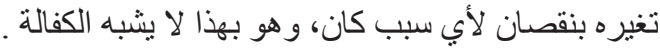

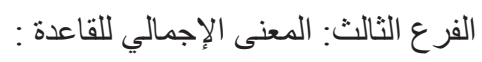

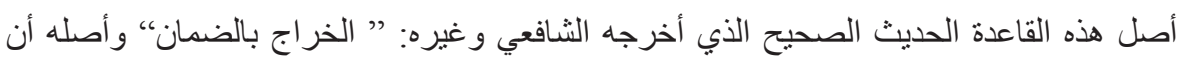

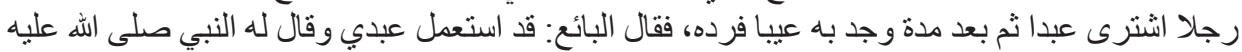

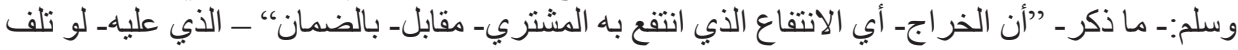

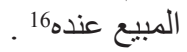

قال أبو عبيد17: "الخر اج في هذا الحديث غلة العبد، يشتريه فيستعله زمانانا ثم بعثر على على عيب دلسها

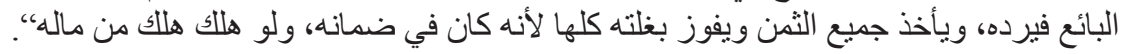

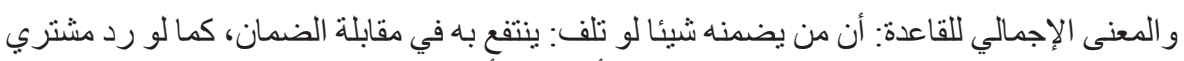

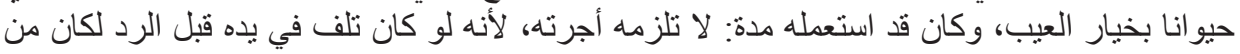

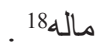

أو أن من بسأل عن ضمان شيء عند التلف، له الحق في منفعته في مقابل تحمله تبعة الهلاك أثناء بقائه عنده .

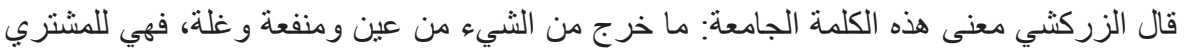

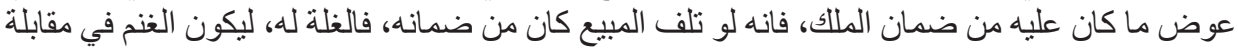
الغرمب .

وتتضح القاعدة بالأمثلة التالية: لو رد المشتري على البائع حيو انا بخيار العيب بعد أن استعمله مدة من الزمن لا تلزمه أجرته من تللك

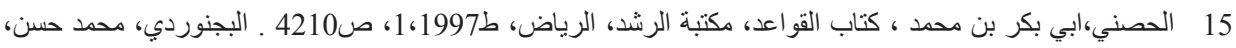

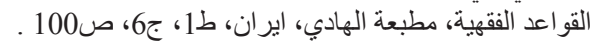

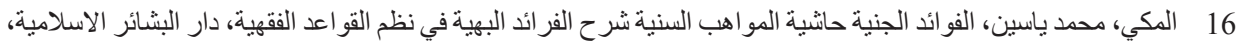

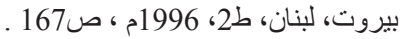

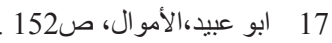

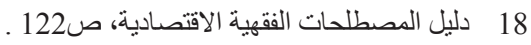

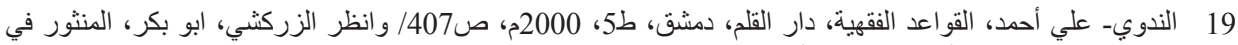

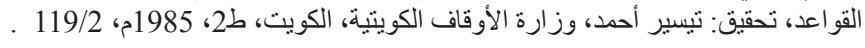


المدة، لأنه لو تلف حال وجوده عنده، كان عليه ضمان منلاه أو قيمته20.

لو كان المبيع شجرة فأتمرت عند المشتري، ثم ردت على البائع، بسبب الاستحقاق أو لتفرق الصفقة

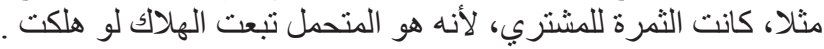

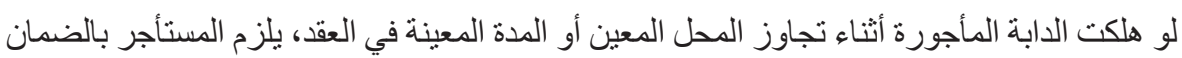

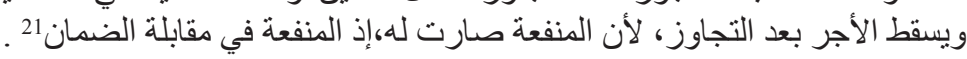
أما إذا تلفت الدابة بلا تعد ولا تقصير، فيلزم المستأجر بأجرة ما قطع من مسافة، لأن الدابة حينئ ليست في ضمانها .

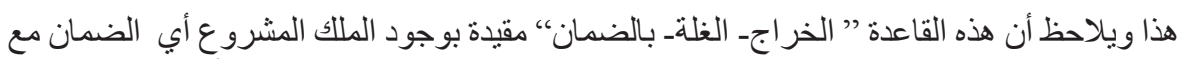

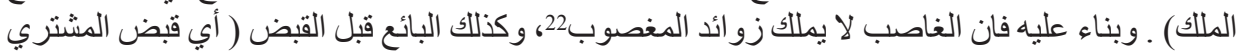

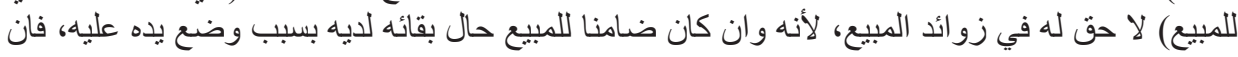

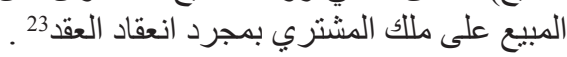
و على هذا يمكن أن نلخص المعنى الإجمالي للقاعدة، أن استحقاق الخر اج و الغلة و الناتج و الربح الناجم

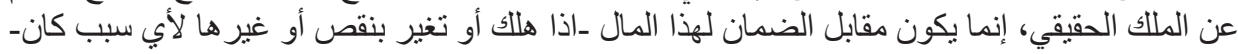

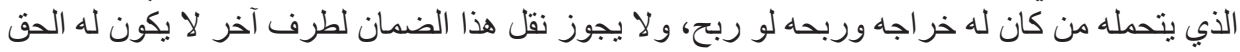
بالخر اج و الغلة.

\section{المبحث الثاني:حقيقة قاعدة الخراج بالضمان: \\ المطلب الأول: تأصيل القاعدة:}

أـ أصل هذه القاعدة حديث صحيح رو اه أحمد و أبو داوود و الترمذي و النسائي و ابن ماجه و ابن حبان

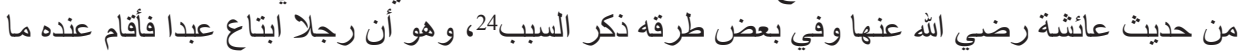

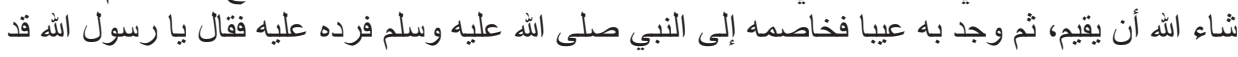

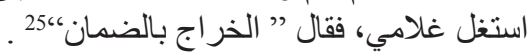
وذكر فخر الإسلام هذا الحديث في أصوله أن هذا الحديث من جوامع الكلم لا يجوز نقله بالمعنى 26 .

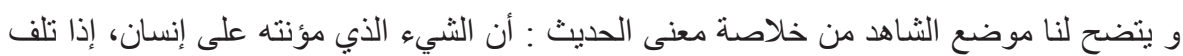

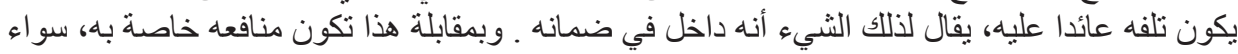

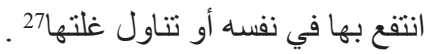
قال أبو عبيد28: "الخر اج في هذا الحديث غلة العبد، يشتريه فيستعله زمانا ثم يعثر على عيب دلسه

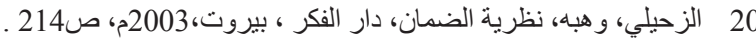

$$
\begin{aligned}
& 21 \text { 2 } 20
\end{aligned}
$$

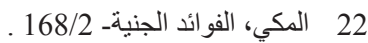

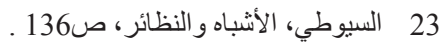

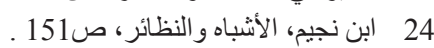

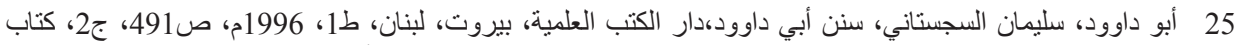

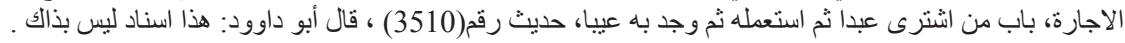

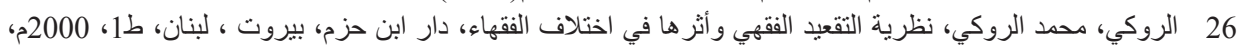

ص371.

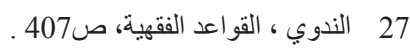

28 
البائع فيرده ويأخذ جميع الثمن ويفوز بغلته كلها لأنه كان في ضمانه، ولو هلك هلك من ماله،؛. وخر اج الثيء: ما حصل منه، والذي يكون منه بمقابلة الضمان ما كان منفصلا غير منو لد كالكسب

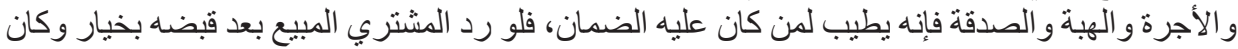

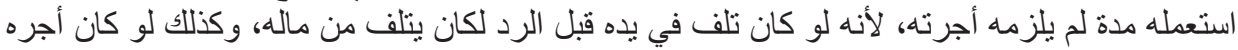

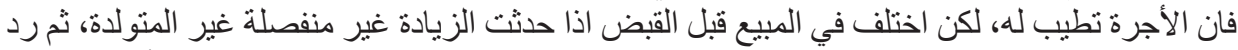

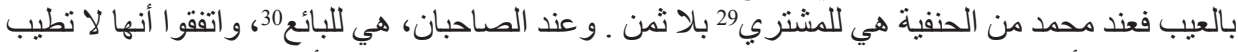

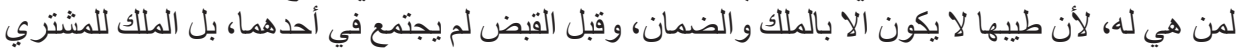

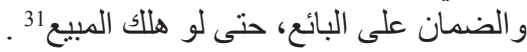

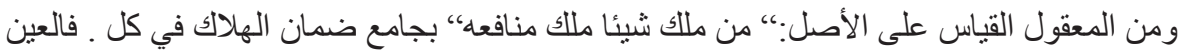

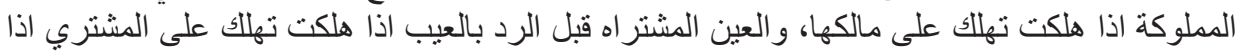
كانت في يده فله منفعتها

\section{المطلب الثاني:تحليل القاعدة:}

هذه القاعدة تتكون من الموضوع و الحكم الكلي ومناط الحكم. .

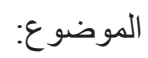

هو الخراج أو الغلة العين المملوكة أو الزيادة الخاصة في العين، وهذه الزيادة إما أن تكون متصلة

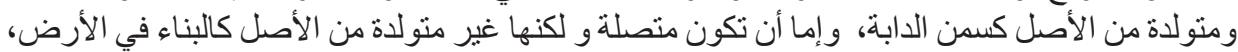

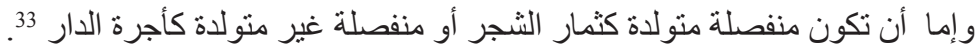

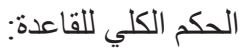

هو أن غلة العين تملك لمن وجب عليه الضمان .

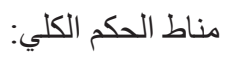

الضمان، حيث يتعلق الحكم بمن وجب عليه الضمان .فلما كان الإنسان بريء الذمة غير مطالب بأي

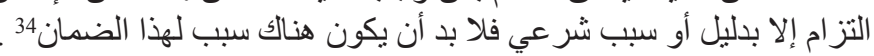

$$
\text { المطلب الثالث: أسباب الضمان: }
$$

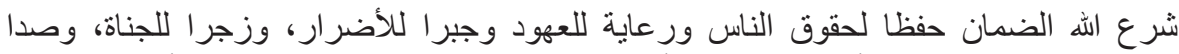

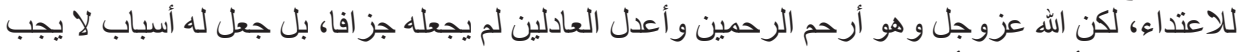
بدونها، و من أهم هذه الأسباب:

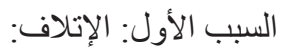

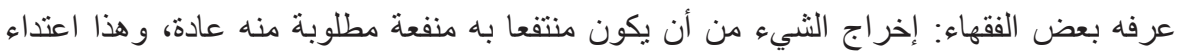

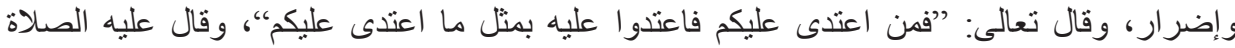

$$
\begin{aligned}
& 29 \text { الكاساني، علاء الدين أبي بكر بن مسعود، بدائع الصنائع، دار احياء التزراث ، بيروت، 1998م، ج6، ص165 . }
\end{aligned}
$$

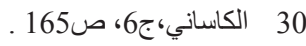

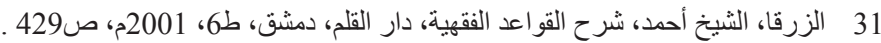

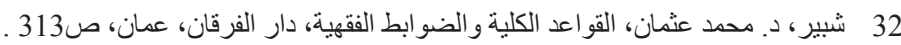

$$
\begin{aligned}
& 33 \text { 3بير، } 32
\end{aligned}
$$

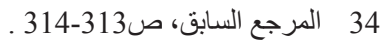


و السلام:“"لا ضرر ولا ضرار"، ، وقد تقرر نفي الضرر من حيث الصورة فيجب نفيه من حيث المعنى

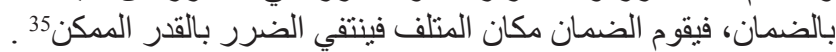

$$
\text { السبب الثاني: وضع اليد: }
$$

يطلق الفقهاء اليد ويقصدون بها من له القدرة على التصرف في العين بذاته كالمالك، أو بأمر كالموكل،

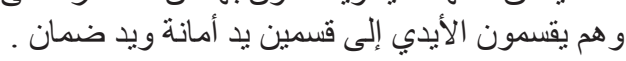

ويد الضمان تقسم إلى قسمين:

اليد العادية: وهي التي قبضت العين لمنفعتها دون إذن من المالك كالسارق و الغاصب3ن فئ.

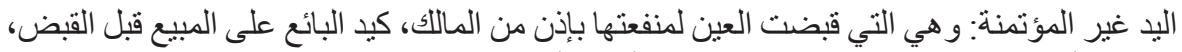

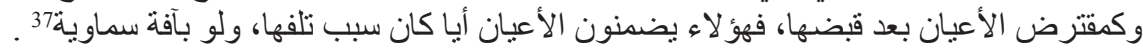

أما بالنسبة ليد الأمانة فهي اليد التي قبضت العين لا بقصد التملك بل نيابة عن المالك، فكان قبضها لإنها

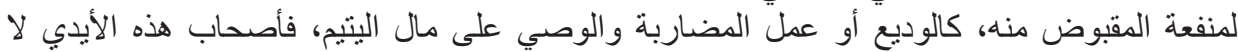

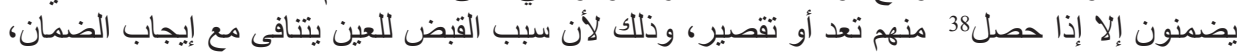

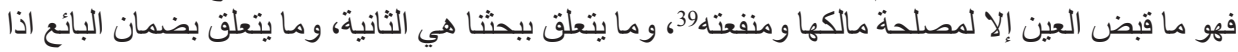
قبض المبيع في بيع المرابحة الابن المبن السبب الثالث: العقد:

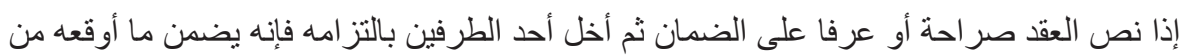

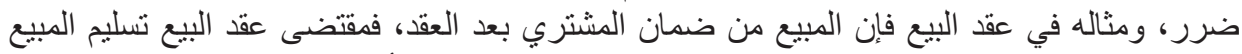

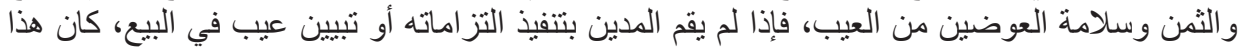
الأمر مستوجبا للضمان وسمة العوضن

\section{المبحث الثالث: بيع المرابحة في البنوك الإسلامية وعلاقته بقاعدة الخراج بالضمان المطلب الأول: بيع المرابحة وحكمه عند الفقهاء:}

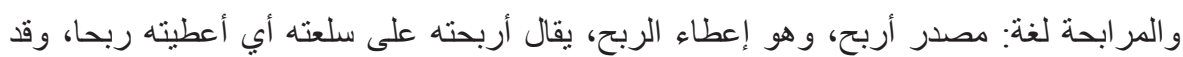

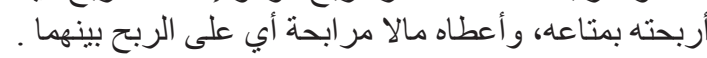

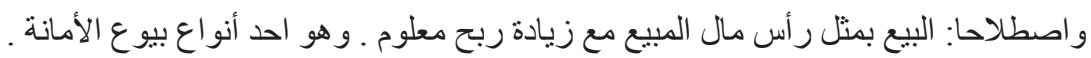

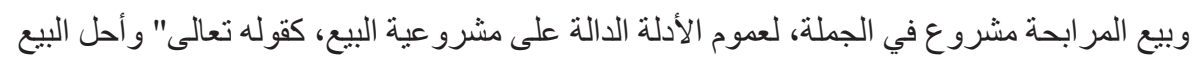

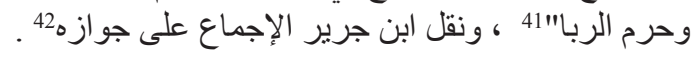

35 الكاساني، علاء الدين أبي بكر بن مسعود، بدائع الصنائع، دار احياء التراث ، بيروت، 1998م، ج6، ص165 ـ

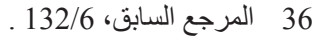

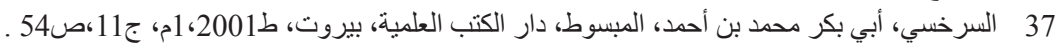

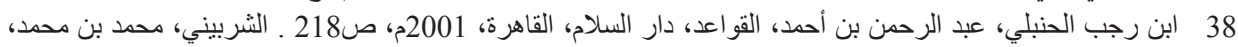

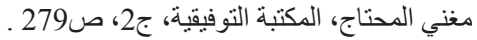

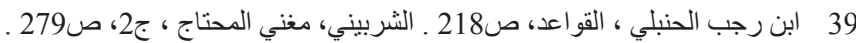

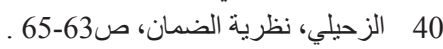
41

42 ابن جرير، محمد بن جرير الطبري، اختلاف الفقهاء، دار الكتب العلمية، بيروت، لبنان، 1999، ص75 . 


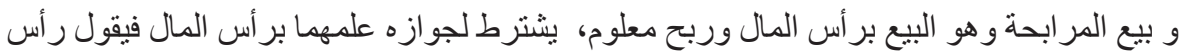

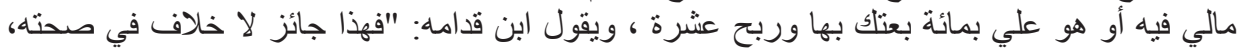

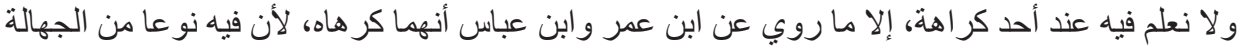

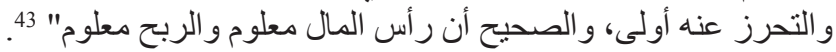

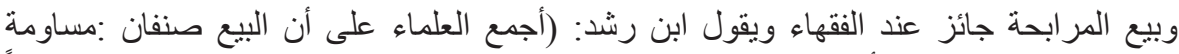

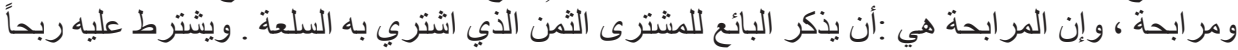

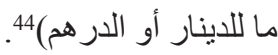

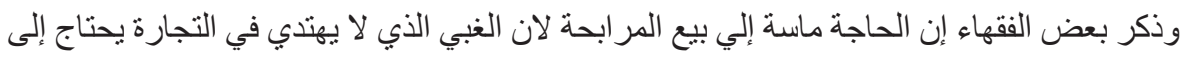

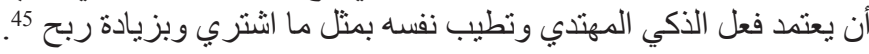

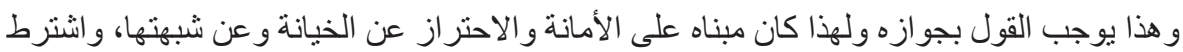

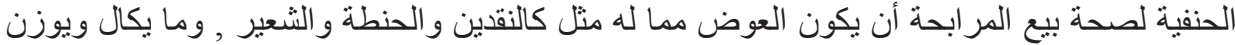

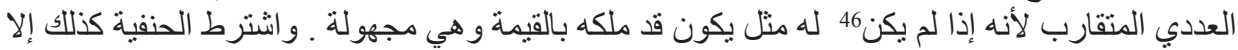

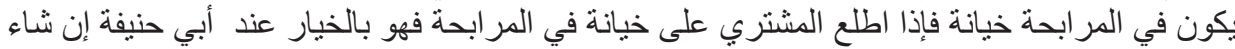

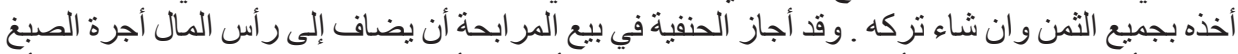

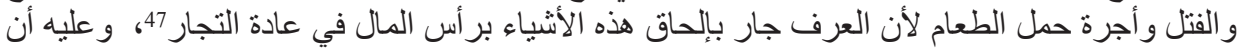

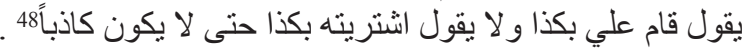

\section{المطلب الثاني: بيع المرابحة في المصارف الإسلامية ( بيع المرابحة للآمر بالثراء) :}

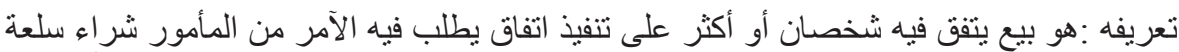

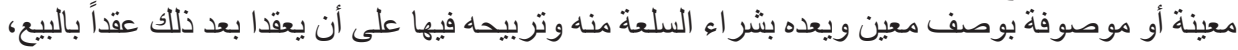

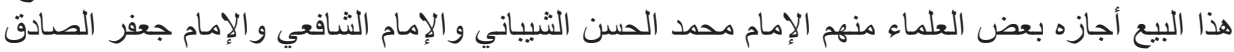

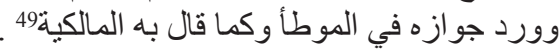

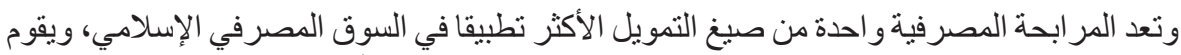

البنك من خلال هذه الصيغة بشر اء ما يحتاجه العملاء من سلع استهلاكية وأصول إنتاجية.

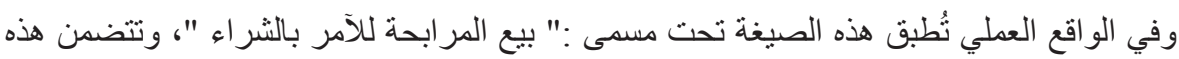

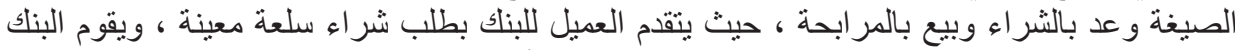
بالشر اء ثم بيعها للعميل مع ربح متفق عليه ويتم السداد على أقساط دورية. وقد تبين من خلال البيانات المنشورة للبنوك السعودية أن صيغة المر ابحة تستحوذ على ما بين

43 ابن قدامة، عبد الله بن أحمد، المغني على مختصر الخرقي، دار الكتب العلمية، بيروت، لبنان، ط1 ، 1994م، ج4، ص129 صائ

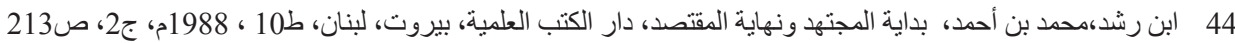
45 المكاشفي، طه الكباشي، بيع المر ابحة و التقسيط ودور ها في المعاملات المصرفية في الفقه الإسلامي بحث مقدم للاورة الثامنة

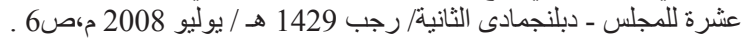

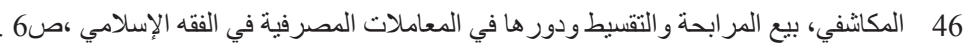

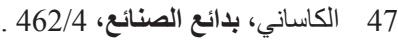

48 المكاشفي طه الكباثي، بيع المر ابحة و التقبط ودور ها في المعاملات المصرفية 49

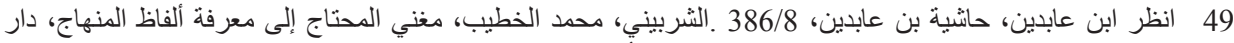

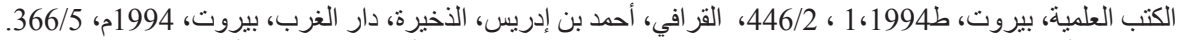

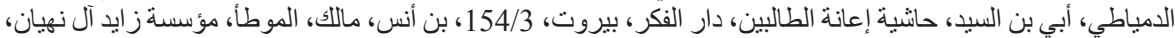

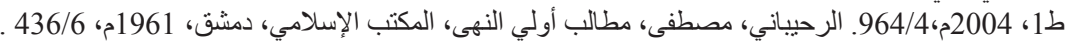


30 - 35 \% من حجم التمويل الممنوح للعملاء بالسوق المصرفي السعودي وذللك خلال الفترة من عام 2000 - 2005م ، ويرجع ذللك إلى العديد من الأسباب من أهمها:

-1 أن المر ابحة سهلة الفهم و التطبيق سو اء للمتعاملين أو العاملين بالمصارف العباب الإسلامية.

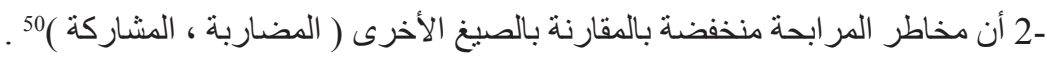

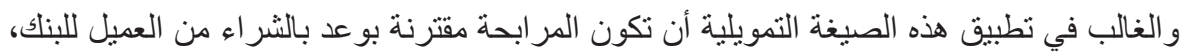

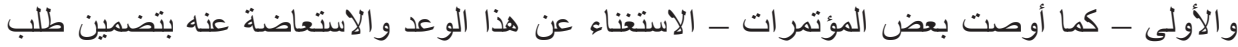

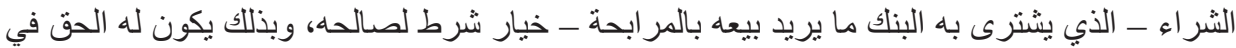

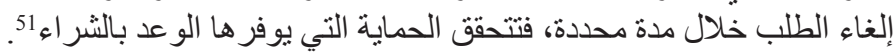

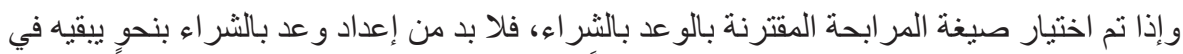

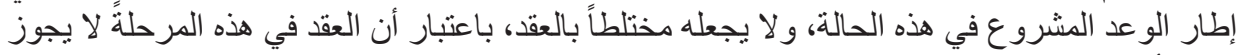

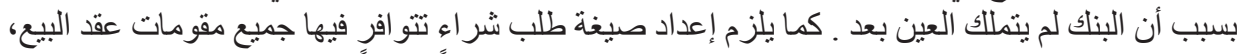

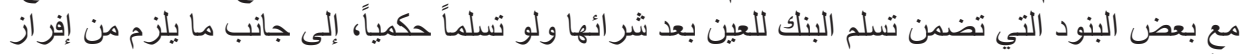

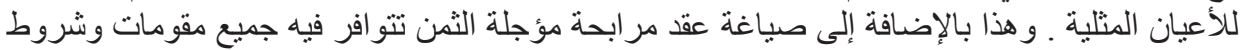

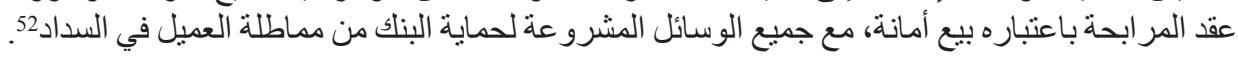

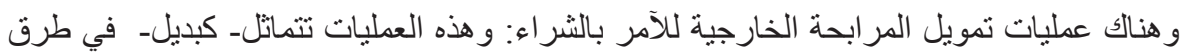

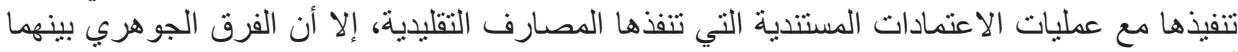

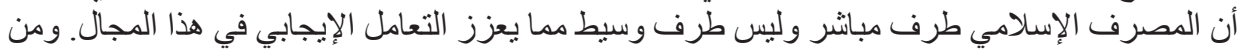
حيث آلية العمل في هذّه العمليات بمكن إيجاز ها بما يلي: الإني

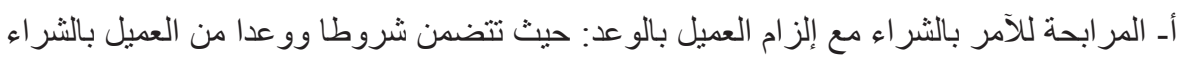

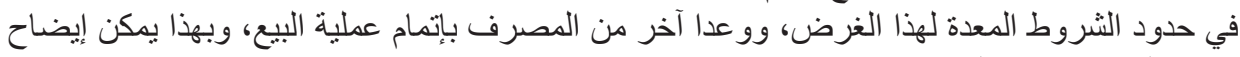

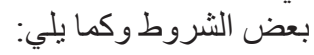
-1 تملك السلعة من قبل المصرف بعقد صحيح. -2 يعرض المصرف السلعة على العميل بعد تملكها من أجل الإيفاء بو عده حيث يؤسس على ذلك بلك عقد بيع مر ابحة. -3 قد يستدعي الأمر في بعض البيوع دفع ما يسمى هامش الجدية الذي أشرنا له في حينه عند نوقيع

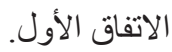

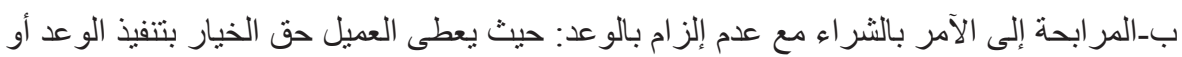

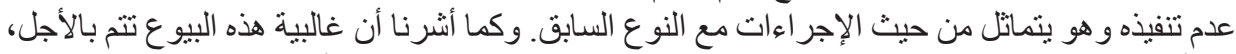

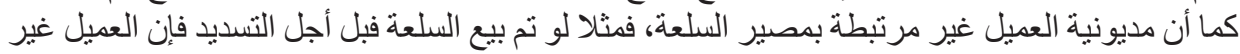
ملزم بتسديد الثمن فورا إلا إذا رغب بذبط بللكئ5.

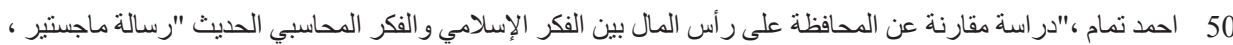

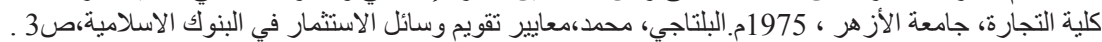

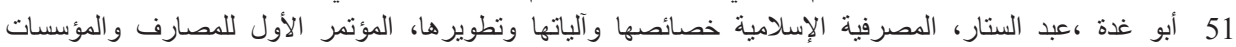

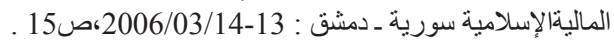

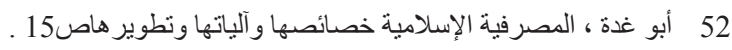
53 الثرع، مجيد، النواحي الإيجابية في التعامل المصرفي الإنية الإسلامي ، بحث مقدم للمؤتمر العالمي لكلية الاقتصاد و العوم

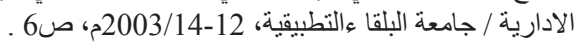


المطلب الثالث: مخالفة بعض تطبيقات بيع المرابحة للآمر بالثراء لقاعدة الخراج بالضمان - مثال تطبيقي البنك الإسلامي الأردني-:

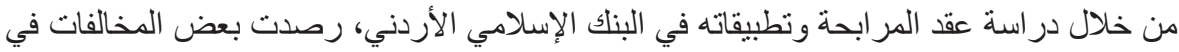

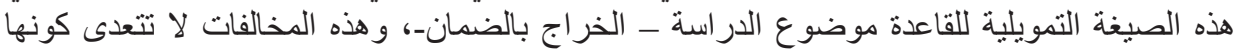

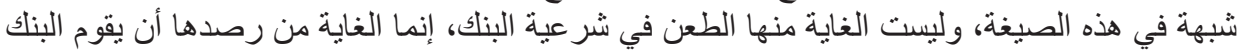

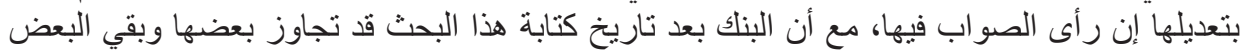

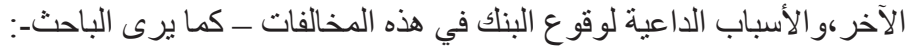

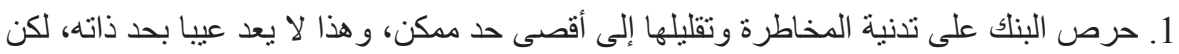
الإنشكالية فيما يتبعه من اجراءات.

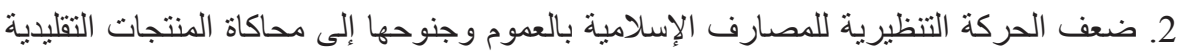

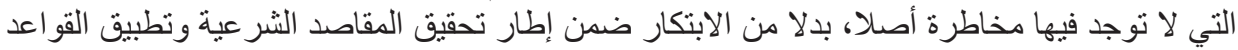
الفقهية المتمدة مثل هذه القاعدة.

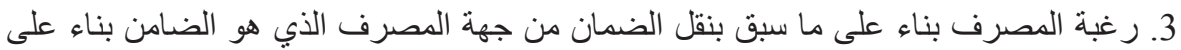

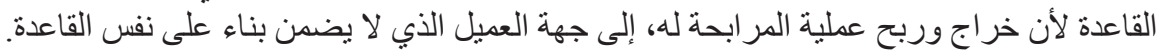

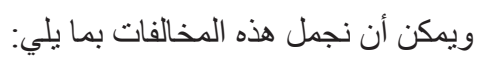

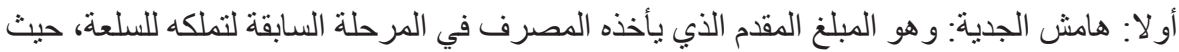

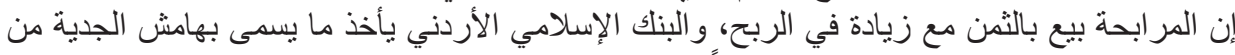

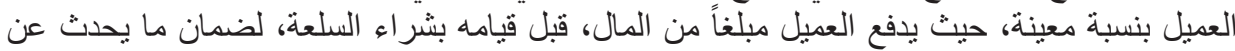
أضر ار متوقعة على البنك من هذه المعاملة.

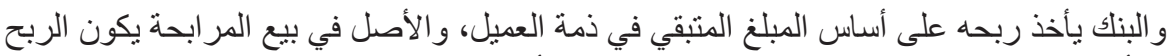

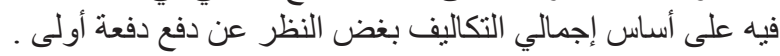
و هذا يُخرج المر ابحة كما يجريها البنك الإسلامي الأردني من دائرة المر ابحة المعلومة في الفئه الفقه.

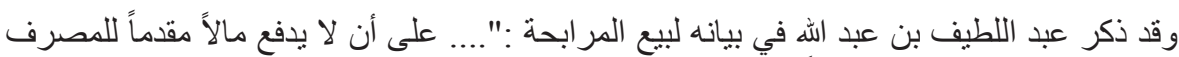

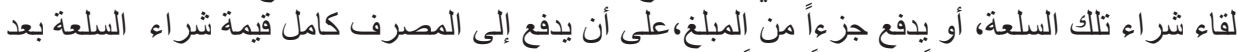

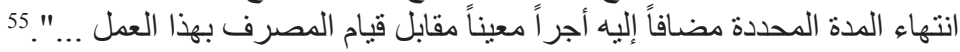

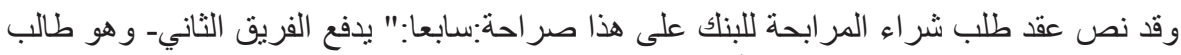

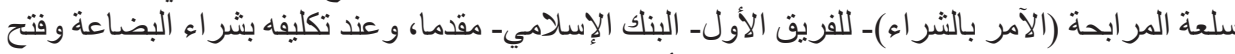

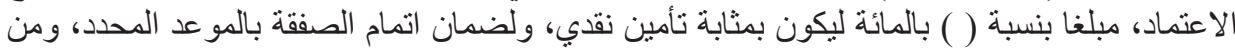

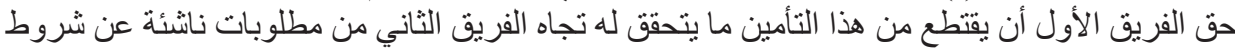

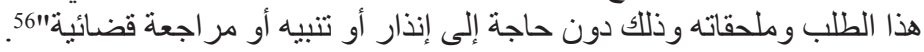

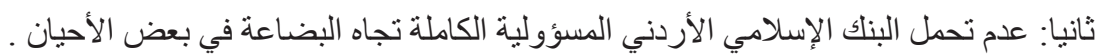

54 الخطيب، د. محمود إبر اهيم مصطفى ، من صيغ الاستثمار الإسلامية المر ابحة الداخلية في البنك الإسلامي الأردني للتمويل

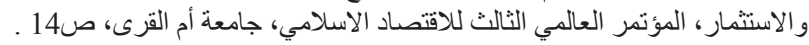
55 العبد اللطيف :عبد الطيف بن عبد الله، الإيجاز في مبادئ الاقتصاد الإسلامي،دار ابن حزم الإن ـ المكتبة المكية، 1418هـ 1997- 
إن البنك الإسلامي الأردني لا يتحمل أية مسؤولية تجاه البضاعة التي يشتريها على حساب الآمر

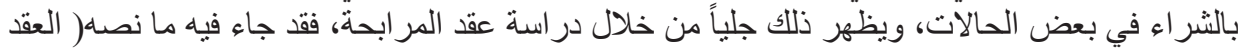

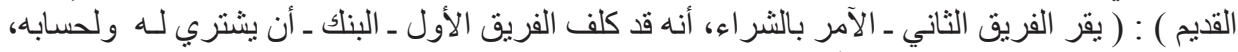

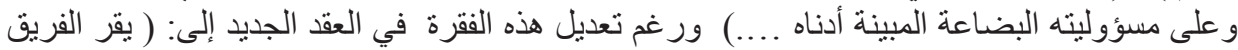

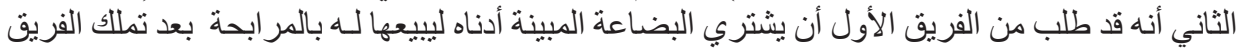

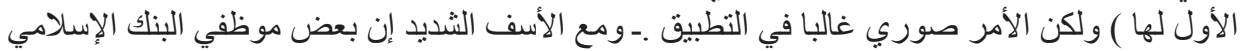

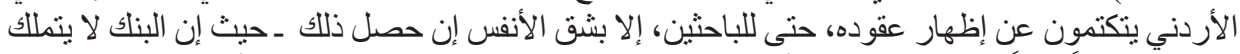

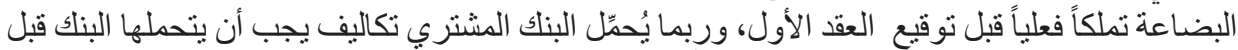

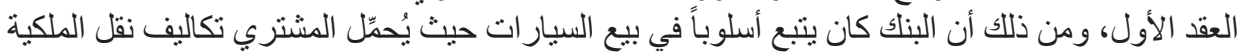

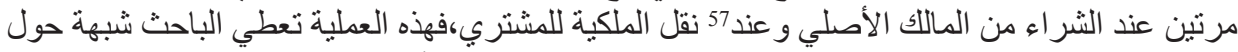

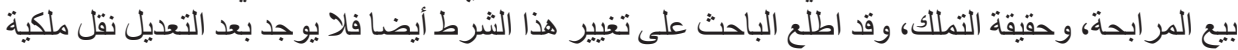
مرنين، بل يوجد عقد مبايعة داخلي بين البنك و البائع يستغنى فيه عن نقئ نقل الملكية في المرة الأولى.

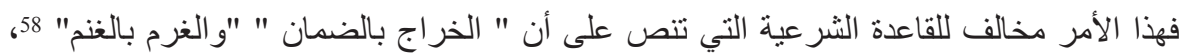

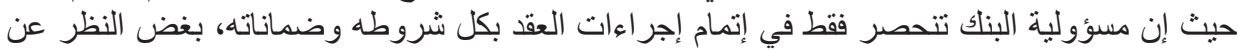

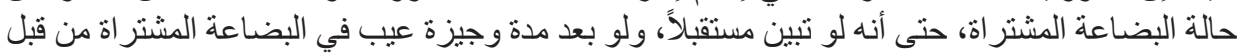

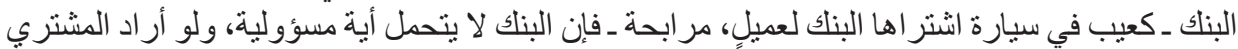

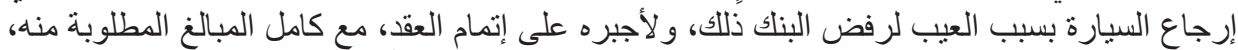

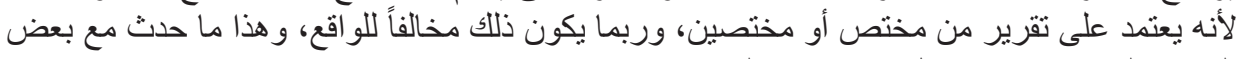

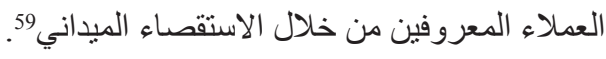
إن عمل البنك الإسلامي الأردني مناف أيضاً لبعض ما جاء في في قرار الت ات مجمع الفقه الإسلامي في دورة

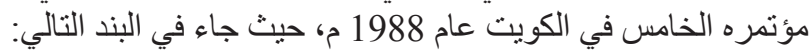
أو لا : ( أن بيع المرابحة للآمر بالثر اء إذا وقع على سلعة بعد دخولها في ملك المأمور، وحصول

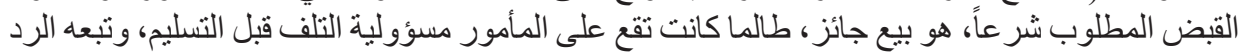

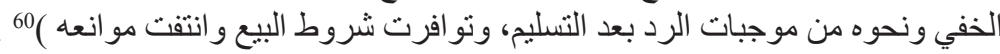

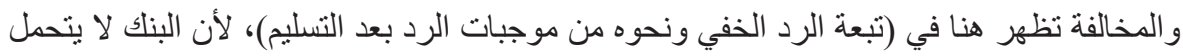
هذه التبعات بعد التسليم للعمبل. ورغم ذلك فالبنك يعمل بكل وسائله ليضمن حقه، كما ذكرنا سابقا ما جاء في عقد المر ابحة للآمر

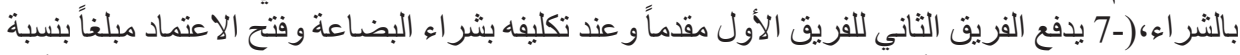

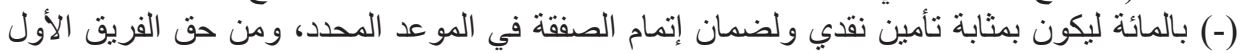

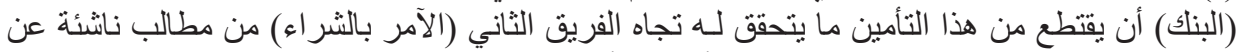

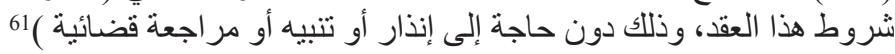
و هذا يؤكد أن عملية البيع لبيت عمليتين منفصلتين بل هما عملية واحدة، وو اقع عقد بيع المر ابحة في

57 الخطيب، من صيغ الاستثمار الإسلامية المر ابحة الداخلية في البنك الإسلامي الأردني للتمويل و الاستثمار ، ص14

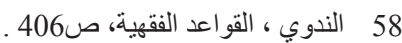

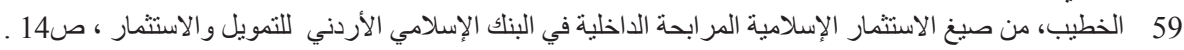

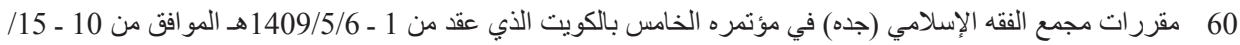

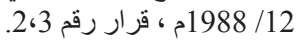




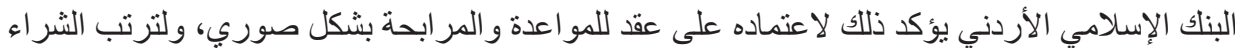

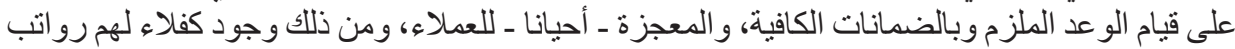

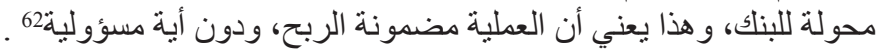

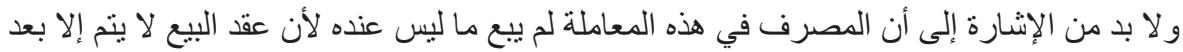

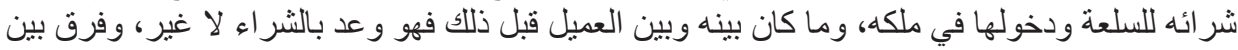

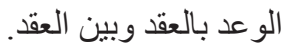

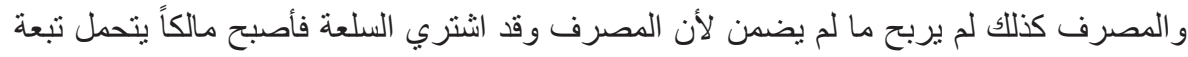

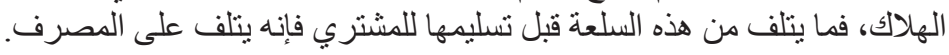

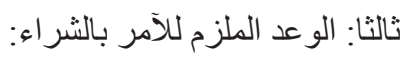

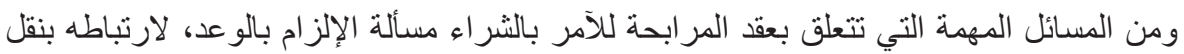

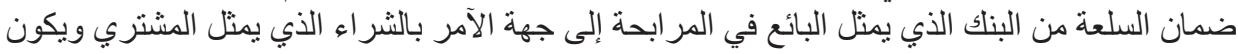

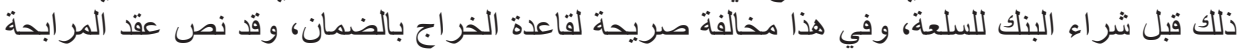

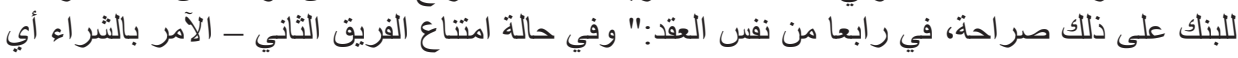

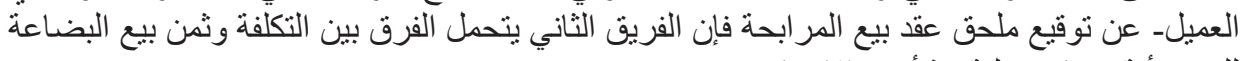
للغير وأية خسائر فعلية تنشأ عن الامتناع".

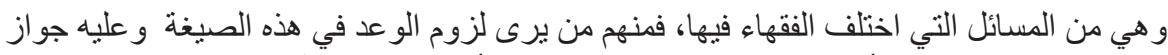

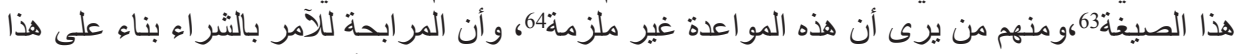

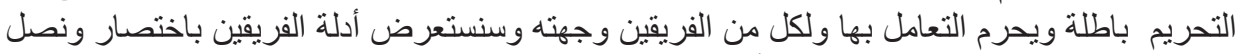
إلى القول الر اجح إن شاء الله بعد دراسة أدلة الفرئل الفريقين:

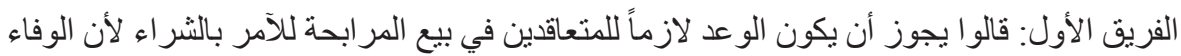

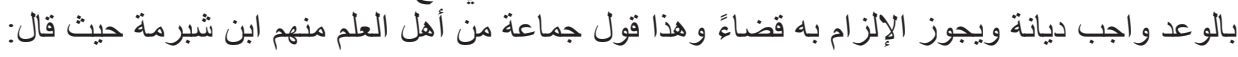

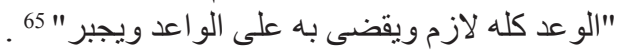

\section{وقد استدلو ا على قولهم بأدلة كثيرة منها:}

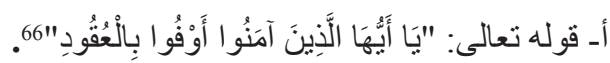

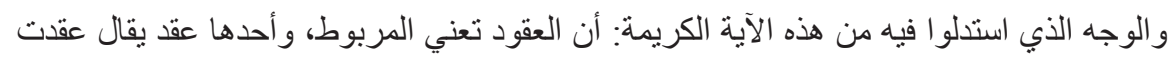

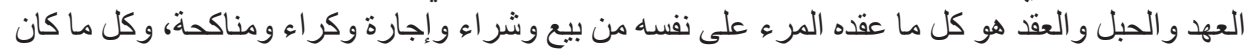

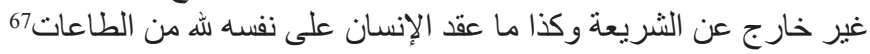

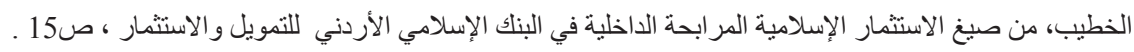

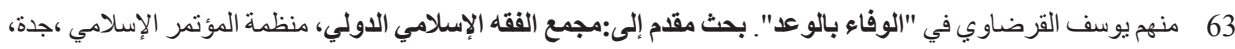

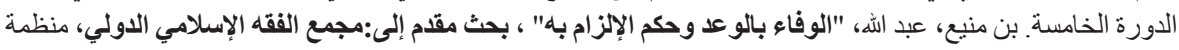

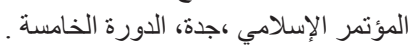
64 منهم رفيق المصري، "الوعد الملزم في معاملات المصارف الإسلامية"، مجلة جامعة الملك عبد العزيز، الاقتصاد

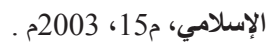
65 ابن حزم، علي بن أحمد، المحلى بالآثار، دار الكتب العلمية، بيروت، ط1، 2003، 2003م، 278/6 ـ 66 67 القرطبي، محمد بن أحدد، الجامع لأحكام القرآن، دار عالم الكتب، الرياض، 2003م، 32/6 . 


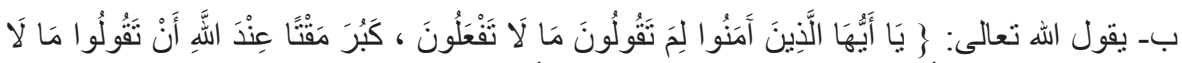

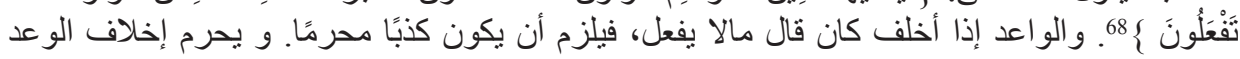
696

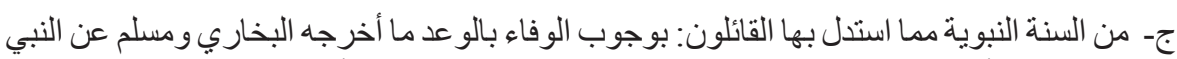

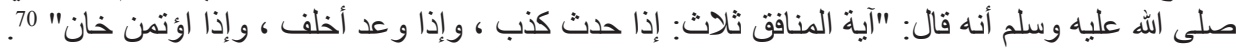

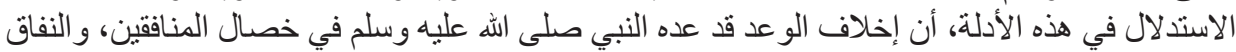

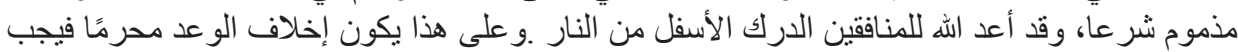

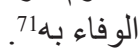

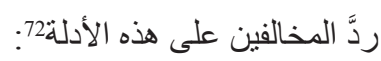

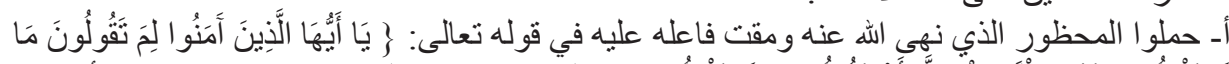

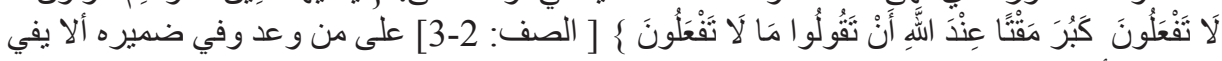

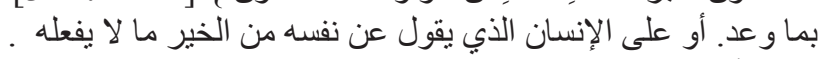

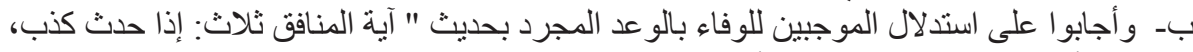

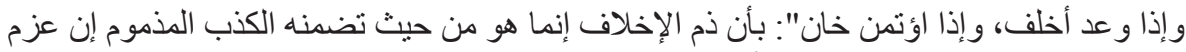

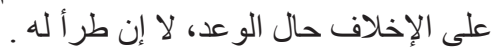
يمكن أن يضاف إلى ذلك أن اخلاف الو عد الو ارد لا يقصد منه انثاء الو عد اله الهداء في عقود المعاوضات،

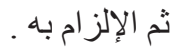
أدلة القائلين بعدم جواز الإلز ام بالو عد:

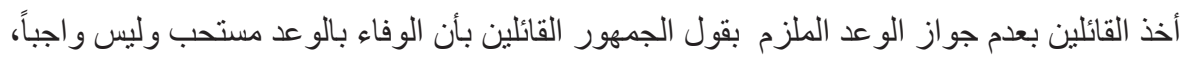

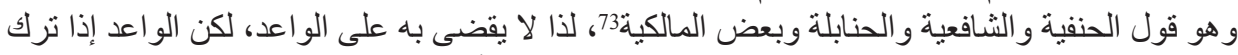

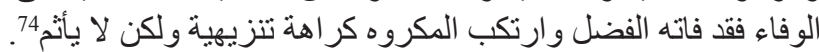

$$
\text { وقد احتج الجمهور على قولهم بما بأتي: }
$$

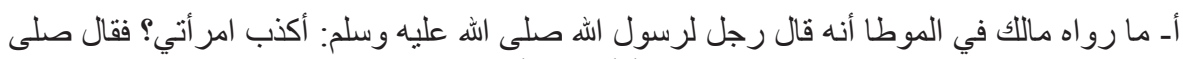
الله عليه وسلم لاخير في الكذب: فقال: يا رسول الله أفأعدها و أقول لهاب؟ قال عليه الصليه الصلاة والسلام: لا جناح عليك5.75. بـ عن زيد بن أرقم عن النبى ـصلى الله عليه وسلم- قال " إذا و عد الرجل أخاه ـ ومن نيته أن يفى

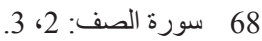

69 68

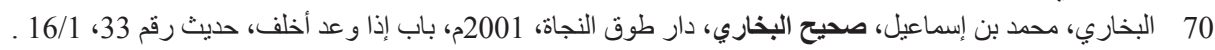

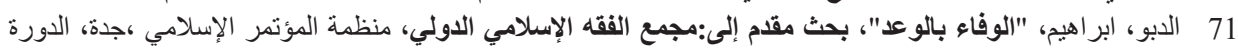

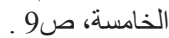

72 حماد، نزيه، "الوفاء بالو عد في الفقه الإسلامي تحرير النقول ومراعاة الاصطلاح" ، بحث مقدم إلى:مجمع الفقه الإسلامي

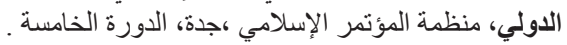

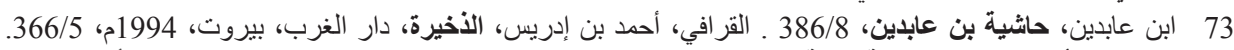

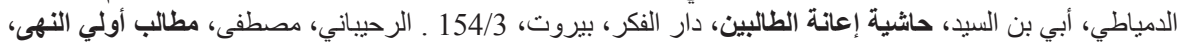

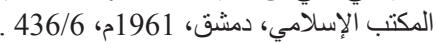

$$
\begin{aligned}
& 7474
\end{aligned}
$$

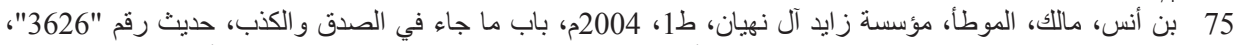

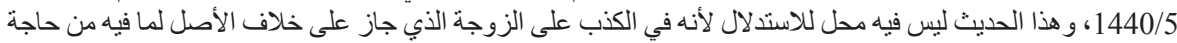


له - فلم يف ولم يجئ للميعاد فلا إثم عليه "76".

ثـ ويمكن الاستدلال لر أي الجمهور بأن الوعد تبرع محض من الو اعد ولا دليل على وجوب التبرع على أحد . م- م.

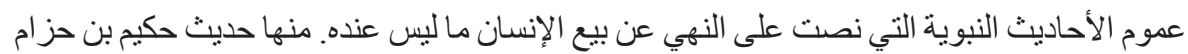

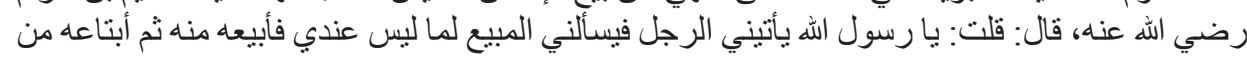

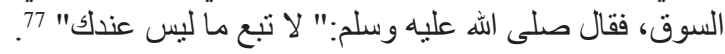

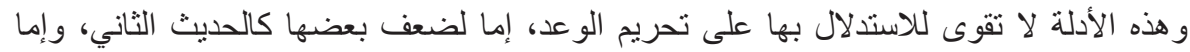

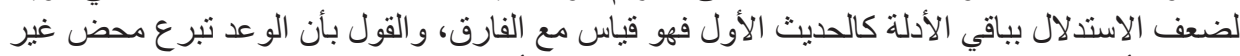

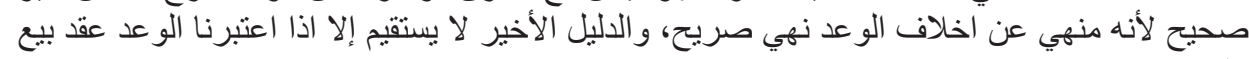
وليس مجرد و عد.

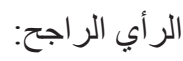

الذي يظهر أن هذه المسألة وهي الوفاء بالو عد من المسائل الخلافية التي تعددت فيها أنظار الفقهاء

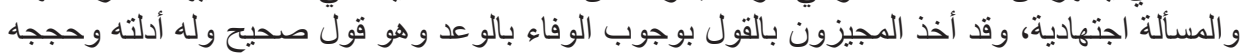

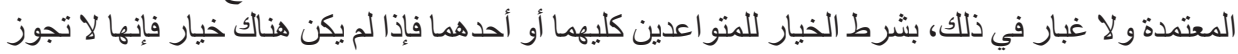

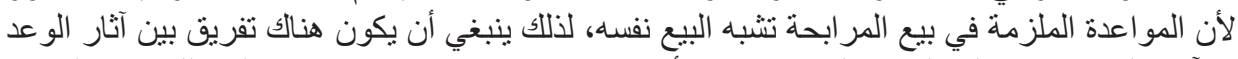

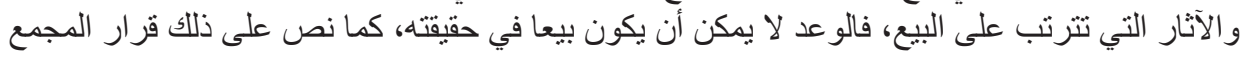

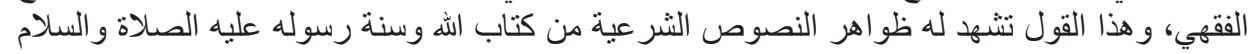
وبه قال طائفة من الصحابة ولفية والتابعين.

وقد ترجم الامام البخاري في صحيحه (باب من أمر بإنجاز الوعد). وذكر فيه أن الحسن البصري البري

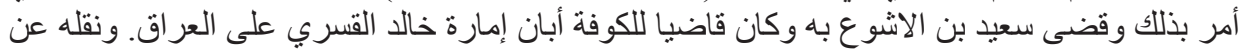

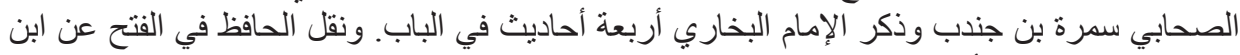

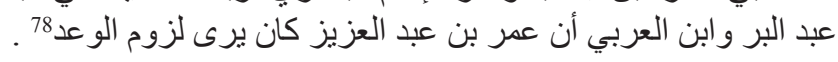

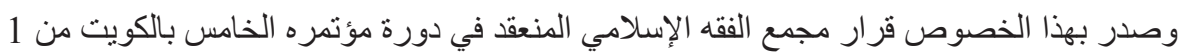

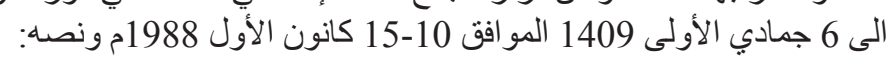

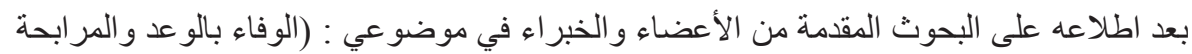

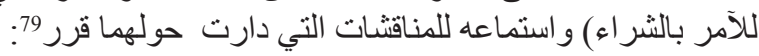
أولاً: إن بيع المر ابحة للآمر بالشر اء إذا وقع على سلعة بعد دخولها في في ملك المأمور وحصول

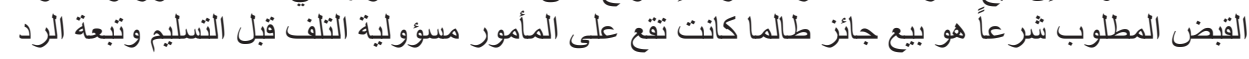

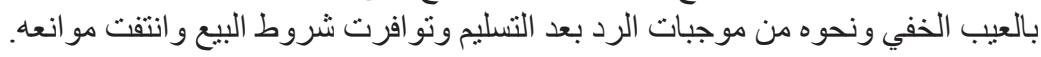
ثانيا: الوعد (وهو الذي يصدر من الآمر أو المأمور على وجه الإنفر اد) يكون ملزماً للو اعد ديانة إلا

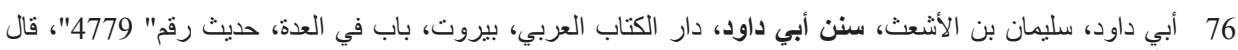

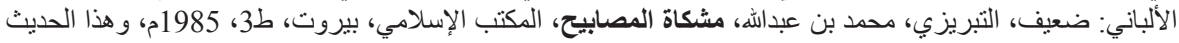

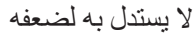

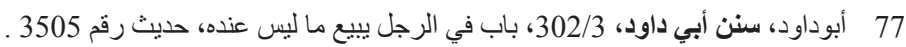

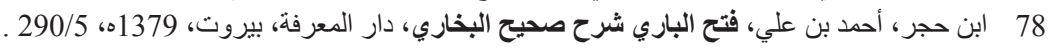

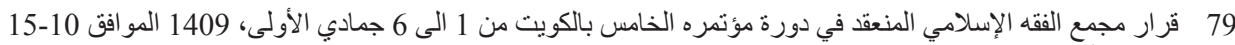
كانون الاول 1988م. 
لعذر. و هو ملزم قضاء إذا كان معلقاً على سبب ودخل الموعود في كلفة نتيجة الوعد ويتحدد أثز الإلزام

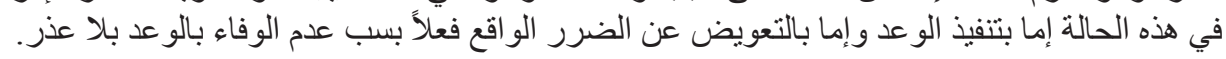
ثالثا: المواعدة (وهي التي تصدر من الطرفين) تجوز في بيع المرابحة بشرط الخيار للمتواعدين

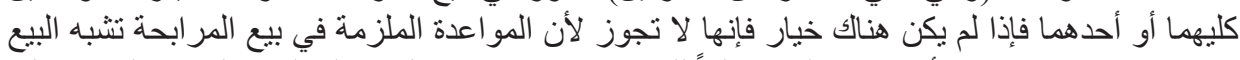

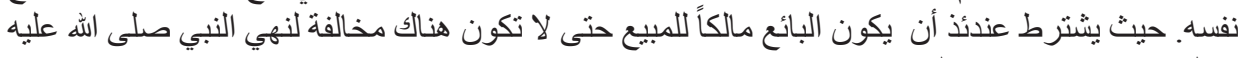

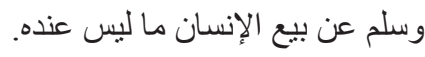

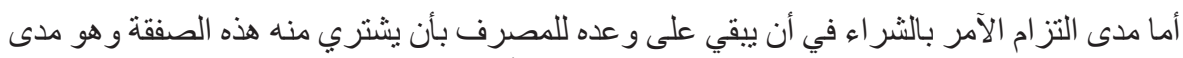

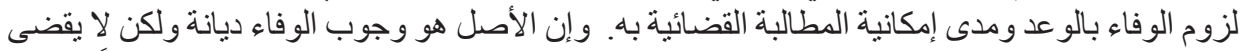

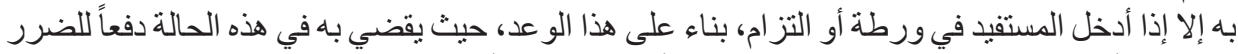

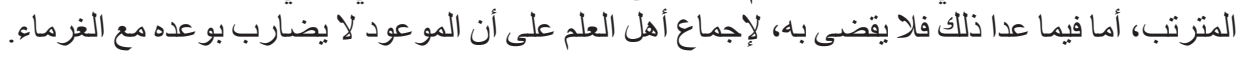

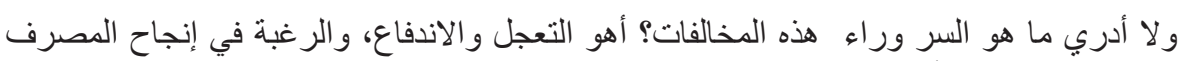
الإسلامي من خلال تتفيذ أكبر قدر من العمليات الاستثمارية. أم هي العقلية الربوية التى ألفت المعاملات الربوية زماناً طويلاً ثم عهد إليها فجأة بتنفيذ الأساليب

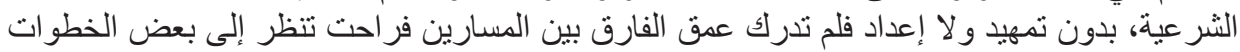

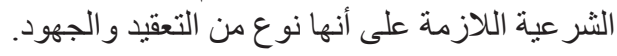
أم ضغوط المنافسة من جانب البنوك الربوية، وشدة وطأتها هي التى أدت ببعض الته العاملين في

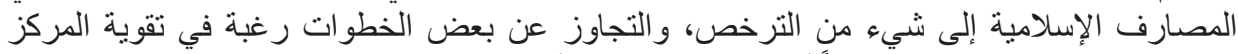
التنافسي للمصرف الإسلامي، وظناً أن نبل الهدف يشفع لأخطاء الوسيلة. وسو اء كان هذا السبب أم ذلك، فإن شيئًا من ذلك لا يبرر اقتحام الشبهات.

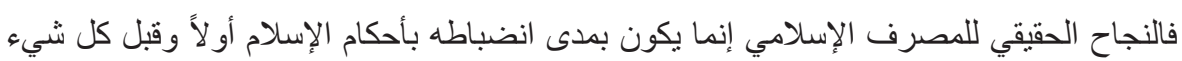

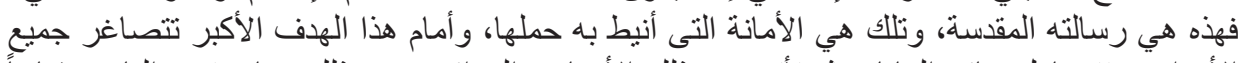

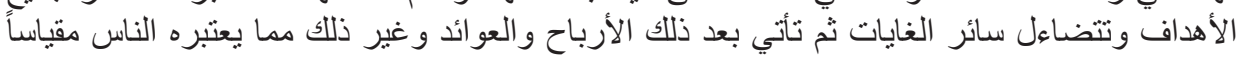
للنجاح. و أخير ا أود أن أشير إلى أن هذا الحكم لا يعني تحريم التعامل مع البنك الإسلامي الأردني، و إنما هي الإني

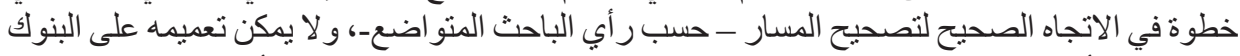

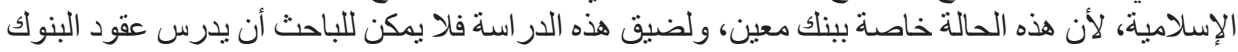

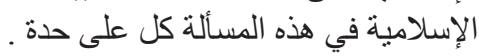




\section{الخاتمة}

النتائج و التوصيات

أو لا: النتائج

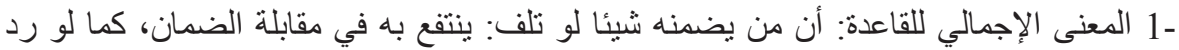

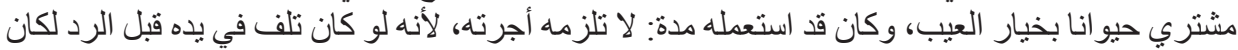

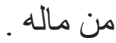

-2 أصل هذه القاعدة حديث صحيح رو اه أحمد و أبو داوود و الترمذي و النسائي و ابن ماجه و ابن حبان

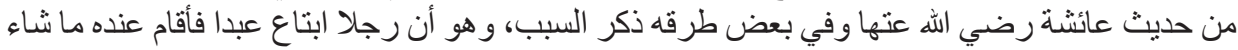
الله أن يقيم، ثم وجد باه عيبا فخاصمه إلى النبي صلى الله عليه وفيه وسلم فرده عليه فقال يا رسول الله قد استغل

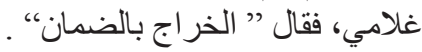

-3 أما بالنسبة لبيع المر ابحة عند الفقهاء فهو اصطلاحا: البيع بمثل رأس مال المبيع مع زيادة ربح

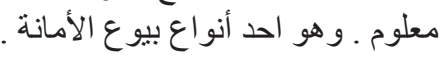

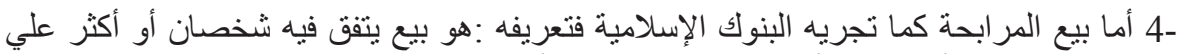

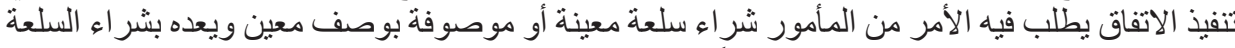

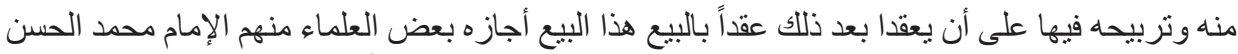

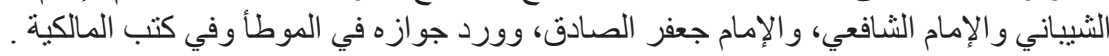

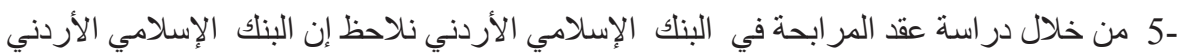

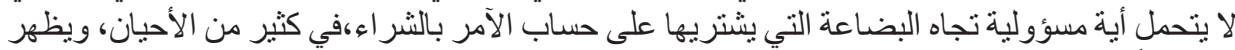

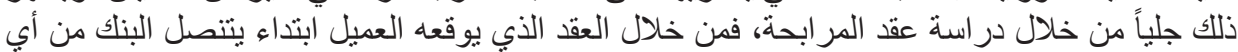

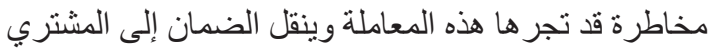
و هذا الأمر مخالف للقاعدة الثرعية التي تتص على أن " الخر اج بالضمان " "و الغرم بالغنم" ، حيث الثيث

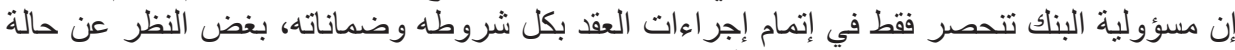

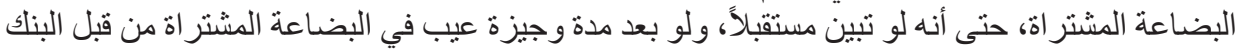

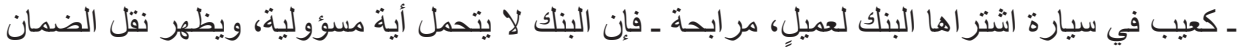

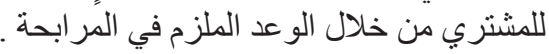

ثنانيا: التوصيات:

عمل أبحاث ودر اسات ورسائل جامعية متخصصة ببحث هذه القاعدة وتطبيقاتها المعاصرة، لما لها من أهمية قصوى في باب المعاملات .

در اسة عقود المر ابحة التي تجريها البنوك الإسلامية كل على حدة لأن هناك من العقود من يخالف هذه

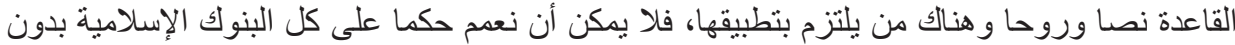

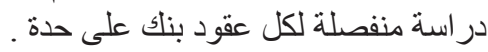

يجب على البنوك الإسلامية أن تراعي عند صياغة عقودها تطبيق وتضمين معاني هذه القاعدة في

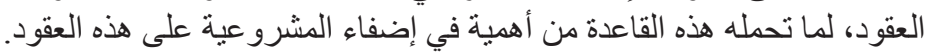


قائمة المصادر والمراجع

ابر اهيم وأحمد الزيات وحامد عبد القادر ومحمد ، المعجم الوسبط، دار الدعوة ، اسطنبول، ط2.

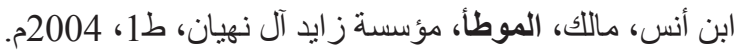
ابن جرير، محمد بن جرير الطبري، اختلاف الفقهاء، دار الكتب العلمية، بيروت، لبنان، 1999. ابن حجر، أحمد بن علي، فتح الباري شرح صحيح البخاري، دار المعرفة، بيروت، 1379هـ

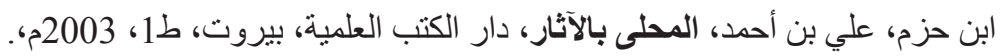

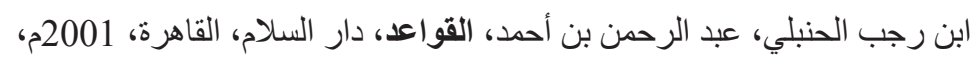
ابن رشد،محمد بن أحمد، بداية المجته ونهاية المقتصد، دار الكتب العلمية، بيروت، لبنان، ط10 . 1988،

ابن قدامة، عبد الله بن أحمد، المغتي على مختصر الخرقي، دار الكتب العلمية، بيروت، لبنان، ط1 ،

ابن نجيم، زين العابدين، الأشباه والنظائر على مذهب أبي حنيفة، مؤسسة الحلبي، القاهرة، 1968م. أبو داوود، سليمان السجستاني، سنن أبي داوود،دار الكتب العلمية، بيروت، لبنان، ط1، 1996م. ابو عبيد، القاسم بن سلام، الأموال، تحقيق: محمد عمارة، دار الشروق، بيروت، ط1، 1989م.

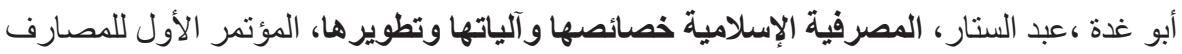

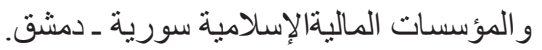

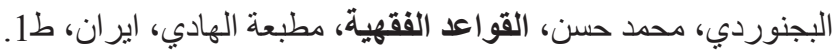
البخاري، محمد بن إسماعيل، صحيح البخاري، دار طوق النجاة، 2001م.

البلتاجي، محمد،معايير تقويم وسنائل الاستثمار في البنوك الاسلامية.

البنك الإسلامي الأردني، عقد المرابحة البنك الإسلامي. تمام، احمد ،"دراسة مقارنة عن المحافظة على رأس المال بين الفكر الإسلامي والفكر المحاسبي الإني

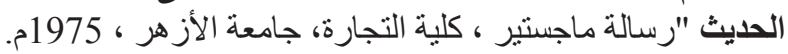
الحصني،ابي بكر بن محمد ، كتاب القواعد، مكتبة الرشد، الرياض، طه، 1997.

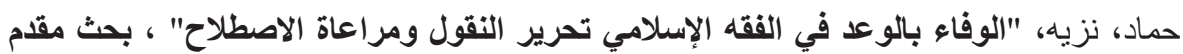

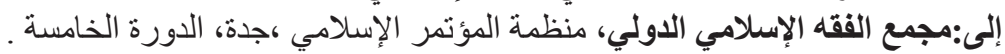

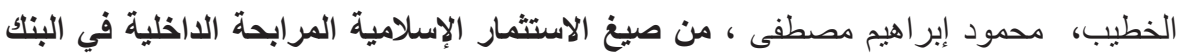

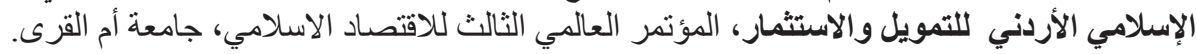
الدبو، ابر اهيم، "الوفاء بالؤوعد"، بحث مقدم إلى:مجمع الفقه الإسلامي الدولي، منظمة المؤتمر الإسلامي ،جدة، الدورة الخامسة. الدمياطي، أبي بن السيد، حاثية إعانة الطالبين، دار الفكر، بيروت. الرحيباني، مصطفى، مطالب أولي النهى، المكتب الإسلامي، دمشق، 1961م .

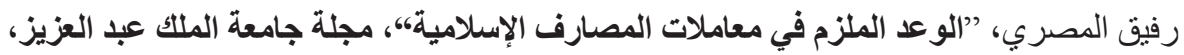
الاقتصاد الإسلامي، مفئ 15، 2003م . 
الروكي، محمد الروكي، نظرية التقعيد الفقهي وأثرها في اختلاف الفقهاء، دار ابن حزم، بيروت ،

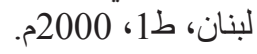

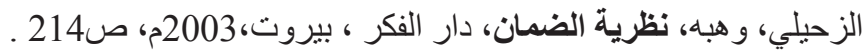

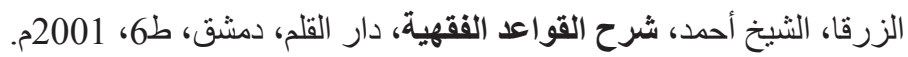

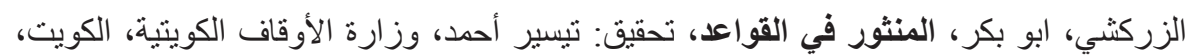

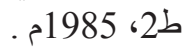

السرخسي، أبي بكر محمد بن أحمد، المبسوط، دار الكتب العلمية، بيروت، العبا، 2001.

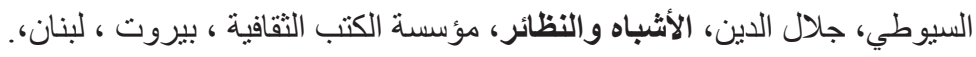

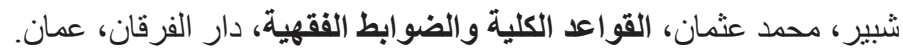

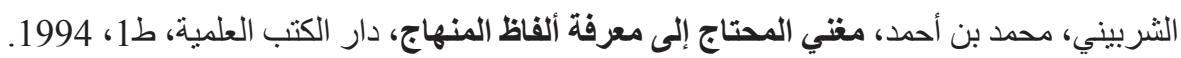

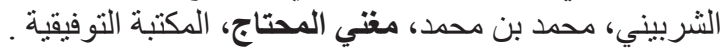

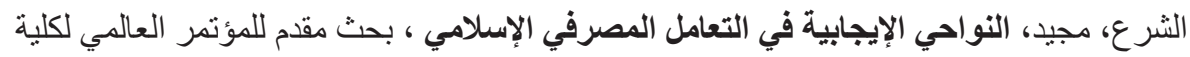

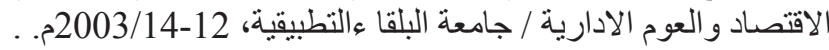
العبد اللطيف :عبد الطيف بن عبد الله، الإيجاز في مبادئ الاقتصاد الإسلامي،دار ابن حزم ـ المكتبة

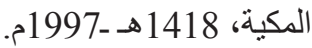

عبد المنعم ، محمود عبد الرحمن، معجم المصطلحات والألفاظ الفقهية، دار الفضيلة ، القاهرة.

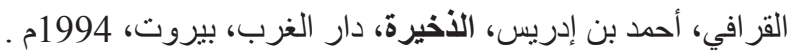

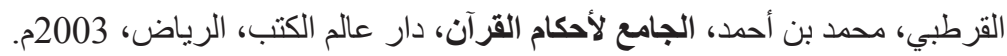

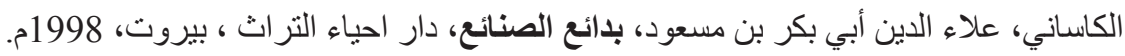

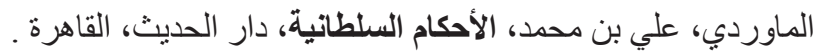

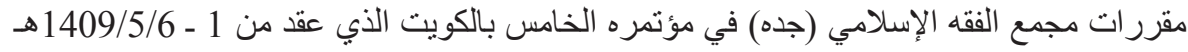

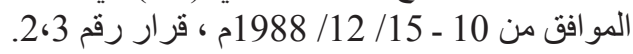

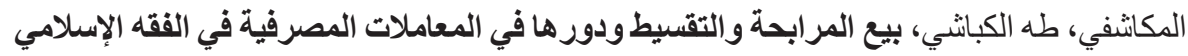

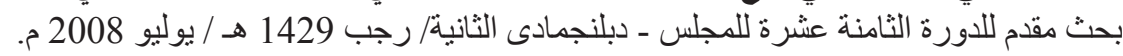

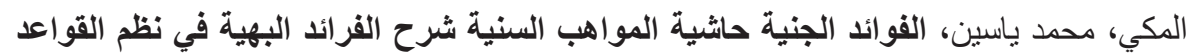

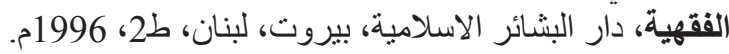

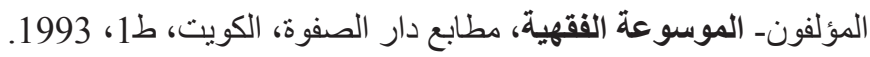
المؤلفون- بيت التمويل الكويني، دليل المصطلحات الفقهية الاقتصادية، ط1، 1992.

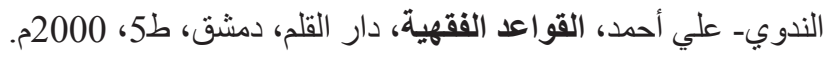

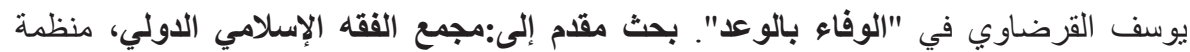

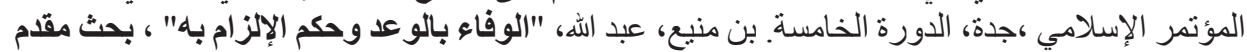

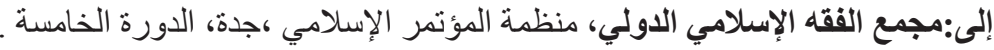


Ibrahim Ahmed Zayat and Hamid Abdul Qadir and Muhammad, almojam alwaseet, Dar Al Dawa, Istanbul, 10 12/15/1988 m, qarar. 2.3.

Ibn Najim, Zine El Abidine, alashbah walndaer ala madhab Abu Hanifa, mosast Al-Halabi, alqaherah, 1968

Abu Daoud, Suleiman Sijistani, Sunan Abu Daud, Dar alkutob alelmeah, Beirut, Lebanon, $1996 \mathrm{~m}$.

Abu Obeid Bin Qasim,alamwal, tahqeq: Mohamed Emara, dar alshrooq, Beirut, $1989 \mathrm{~m}$.

Abu gland, Abdul Sattar, almasrefeah alIslameah khasaesuha wa alyatuha wa tadweroha, almotamar alawal llmsaref wa almosasat Almaleah alisalameah, Soria, Demashq.

Abajnorde, Mohammed Hassan, alqwaed alfeqhea, matbat alhadi, Iran.

Bukhari, Muhammad bin Ismail, Sahih Bukhari, Dar tooq alnajah, 2001.

Beltagui, Mohammed, maeer tqweem wasael alistethmar fe albnook alislameah.

Albank alislame alordone, aqed almurabah.

Tammam, Ahmad, "derasah moqarana fe almohafadah ala ras almal byn alfeker alislame wa alfeker almohasabi al hadeeth," resalt Majster, koleat altejarah, jameat Al-Azhar, 1975.

Alhsna, Abu Bakr bin Muhammad, ketab alqwaed, maktabat ibin rushd, Riyadh, 1997.

Anas Ibn Malik, Muwatta, mosasat Zayed Al Nahyan, i 1.2004 m.

Hammad, nazeeh,alwafaa belwaed fe alfeqih alislame threer alnqool wa moraat al masaleh " bahth moqadam ila mojmaa al Fiqh alislame aldawly, Jeddah,aldawrah alkhamesah.

Al-Khatib, Mahmoud Ibrahim Mustafa, min seagh alestethmar laMurabaha aldakhlyah fe alBank alIslame alordune ,almotamar alalame althaleth leleqtesad alislame, jameat Umm Al Qura.

Aldbo, Abraham, alwafaa bealwad, bahth moqadam ila mojmaa al Fiqh alislame aldawly, Jeddah,aldawrah alkhamesah.

Damietta, Abi Bin alsayd, hasheat iant altalebeen, Dar Al-Fikr, Beirut.

Rahibana, Mustafa, mataleb ole alnoha, almaktab alIslame, Demasheq, 1961.

Rafik al-Masri, "alwad almolzem fe moamlat almasaref alislameah," majlat almalek Abdul Aziz, aleqtesad alislame, 2003 m.

Rocky, Mohammad, Altqaid alfeqhe wathroh fe ekhtelaf alfoqhaa, Dar Ibn 
Hazm, Beirut, Lebnan ,2000 m.

Zoheily, Wahba, nadareat aldaman, Dar Al-Fikr, Beirut, 2003.

Zarqa, Sheikh Ahmed,shareh alqwaed alfeqhya, Dar alqalam, Demashq, $2001 \mathrm{~m}$.

Zarkashi, Abu Bakr, almanthoor fe alqwaed, tahqeq: tiseer Ahmad, wazaret alawqaf alKuwaityah, Kuwait, $1985 \mathrm{~m}$.

Ibn Jarir, Muhammad ibn Jarir al-Tabari, ekhtelaf alfoqhaa, Dar alkutob alelmeah,

Alsarakhse, Abu Bakr Mohammed bin Ahmed, Mabsoot, Dar alktob alilmeah, Beirut.2001.

Suyuti, Jalaluddin,alashbah wa alndaer, mosast alkutob althaqafeah, Beirut, Lebnan,

Shabbir, Mohamed Osman, alqwaed alkoleah wa aldwabed alfeqhea, Dar Al-Furqan, Amman.

El-Sherbini, Mohamed Ben Ahmed, mogne almuhtag ila marefat alfad almenhaj, Dar alkutob alelmeah.

Shara, almajeed, alnwahe alejabeah fe altamol almasrefi alislame, almotamar alilme lokliat aleqtesad / jameat Albalka . 12-14 / 2003. .

Abdul Latif: Abdul Latif bin Abdullah, alejaz fe mbadi aleqtesad aislame, Dar Ibn hazim, 1418 1997m.

Abdel Moneim Mahmoud Abdel-Rahman, mojam almostalhat waalfad alfeqhiah, Dar alfadelah, alqahera.

Quraafi, Ahmed bin Idris, aldakhera, Dar algareb, Beirut, 1994.

Cordobi, Mohammed bin Ahmed, aljame lahkam alKoran, Dar alam alkutob, Riyadh, 2003.

Kasaani, Aladdin Abu Bakr bin Masood, Badaa'i Sanai, Dar ehia alturath, Beirut, 1998.

Ibn Hajar, Ahmed bin Ali ,Fath al-Bari, Dar almarefah, Beirut, 1379.

Mawardi, Ali bin Mohammed, alahkam alsultaneah, Dar al-Hadith, alqahera.

Moqrarat mojmaa al Fiqh alislame aldawly, motmaroh alkhamesah,alkuait

Almkashife, Taha Alkbashi, Murabaha wa altaqseet wa dawrha fe almomalat almasrefeah fe bonook al Islameah ,2008.

Make, Mohammed Yasin, alfwaed aljaneah, Dar albshaer alIslameah, Beirut, Lebnan, $1996 \mathrm{~m}$. 
Almalfon- almawsoah alfeqihea, matabe dar alsafwa, alKuwait, 1993.

Almalfon- , daleel almostlhat alfiqhea aleqtesadea, alKuwait, 1992.

Alnduwi- Ali Ahmed, alqwaed alfiqhea, Dar alqalam, Demasheq, $2000 \mathrm{~m}$.

Yusuf al-Qaradawi to "alwafaa belwaed." bahth moqadam ila mojmaa al Fiqh alislame aldawly, Jeddah,aldawrah alkhamesah.

Ibn Hazm, Ali Ahmed, almohala belathar, Dar alkutob alelmeah, Beirut, i $1.2003 \mathrm{~m}$,.

Ibn Rajab, Abdul Rahman bin Ahmed, alqwaed, Dar es Salaam, alqahera, 2001 ,

Ibn Rushd, Mohammed bin Ahmed, bidayt almojtahed wa nehait almoqtased, Dar alkutob alelmeah, Beirut, Lebanon.1988 m.

Ibn Qudaamah, Abdullah bin Ahmad, almogne ala mokhtasar Al-Kharqi,Dar alkutob alelmeah, Beirut, Lebanon, 1994 m.

Ibin manee, Abdullah, "alwafaa belwaed wa hokom alelzam bhe," bahth moqadam ila mojmaa al Fiqh alislame aldawly, Jeddah,aldawrah alkhamesah. Beirut, Lebanon 0.1999 . 